\title{
Pilot Innovative Territorial Clusters in Russia: A Sustainable Development Model
}

\author{
Evgeniy Kutsenko
}

Evgeniy Kutsenko - Head, Department of Cluster Policy, Institute for Statistical Studies and Economics of Knowledge, National Research University - Higher School of Economics. Address: 11, Myasnitskaya str., Moscow 101000, Russian Federation. E-mail: ekutsenko@hse.ru

\author{
Keywords \\ cluster; cluster policy; open innovation; pilot innovative territorial clusters
}

DOI: $10.17323 / 1995-459 X .2015 .1 .32 .55$

Citation: Kutsenko E. (2015) Pilot Innovative Territorial Clusters in Russia: A Sustainable Development Model. Foresight-Russia, vol. 9, no 1, pp. 32-55. DOI: 10.17323/1995459x.2015.1.32.55

Many countries consider regional clusters as drivers for economic growth and an efficient tool for interaction between actors of a regional innovation system. Numerous financial and non-financial mechanisms of government support are aimed at making these clusters self-sustainable. However the emergence and outlook of a cluster largely depend on a range of basic conditions, so there is always a risk that without government support, the cluster will not be able to shift to the desired trajectory.

The paper analyses Russian experience in supporting pilot innovative regional clusters and suggests indicators of their sustainability.

I

nnovation policy globally over recent decades has seen the concept of clusters spread widely, accounting for growth in business competitiveness via the effective collaboration between nearby actors, enhanced access to technologies, innovations, specialist services, highly qualified executives, etc. Developed clusters have become an effective tool for attracting foreign investment and integrating domestic manufacturers into the global high-tech products market.

From 2012, Russia has implemented a support programme for innovation regional clusters in accordance with the Innovative Development Strategy for the period up to 2020 [Ministry of Economic Development, 2012]. With this in mind, 25 pilot groups were selected and split into two groups which were due to receive support over the next five years [HSE, 2013]. The first group was made up of 14 clusters with the best development programmes, according to experts. In 2013, they received federal budget subsidies worth a total of 1.3 billion roubles and could count on priority support over the next few years. The second group included 11 clusters which did not initially receive any subsidies, but started to benefit from them from 2014.

The cluster selection criteria and procedures and support structures adopted under this programme are on the whole in line with similar European programmes [Kutsenko, Meissner, 2013, pp. 20-24]. It is clear, however, that state funding does not guarantee success. There is the possibility that if the funding is curtailed, the clusters will cease to exist or convert into other forms. Such quasi-clusters could hamper the innovation activity of their members, confining technologies and business models to losing competitiveness [Menzel, Fornahl, 2007, p. 5].

* The paper was prepared within the framework of the Basic Research Program at the National Research University - Higher School of Economics (HSE) and supported within the framework of the subsidy granted to the HSE by the Government of the Russian Federation for the implementation of the Global Competitiveness Program. 
The prospects of accelerating inter-firm collaboration in local innovation systems and creating clusters with different specialties in different regions across Russia will in many ways depend on whether certain clusters are able to transition to a sustainable development model in the next five years. Consequently, it is important to highlight the weaknesses in the operations of pilot clusters and draw up recommendations to accelerate their development.

In this article, we analyse leading state cluster policy practices in certain countries, consider the most important characteristics of a successful cluster, and assess how well Russian cases match these. We also present an overall sustainable development model and summarize results based on applying this model.

\section{Cluster policy study: International and Russian experience}

The scientific and analytical literature has reviewed and analysed almost two decades of targeted cluster development around the world. Summary papers on national policies occupy an important position in this literature. Of particular note is research by the OECD, one of several studies offering intercontinental coverage, as the sample included clusters from France, Germany, Canada, USA, South Korea, and Japan [OECD, 2007]. It presents structured case studies of 26 national cluster development programmes in 14 countries. It should be noted that in view of the fundamental discrepancies in the treatment of cluster policy specific to certain countries, the research tools were not clearly defined. The characteristics of the varying approaches in different parts of the world are provided in Table 1.

The majority of other studies are focused exclusively on European countries and are based on their understanding of the concept of clusters, which explains Europe's leadership in terms of how long the cluster approach has been used and the number of clusters formed. ${ }^{1}$

In 2008, the consultancy firm Oxford Research presented a summary report on national and regional cluster strategies in 31 European countries [Oxford Research, 2008]. It paid particular attention to analysing state initiatives and programmes and the organizations responsible for implementing them.

Another project, the Transnational Alliance of Clusters Towards Improved Cooperation Support (TACTICS) [Pro Inno Europe, 2012], focused on core national programmes in Austria, Belgium, Great Britain, Hungary, Germany,

\section{Table 1. Specific features of approaches to state cluster policy}

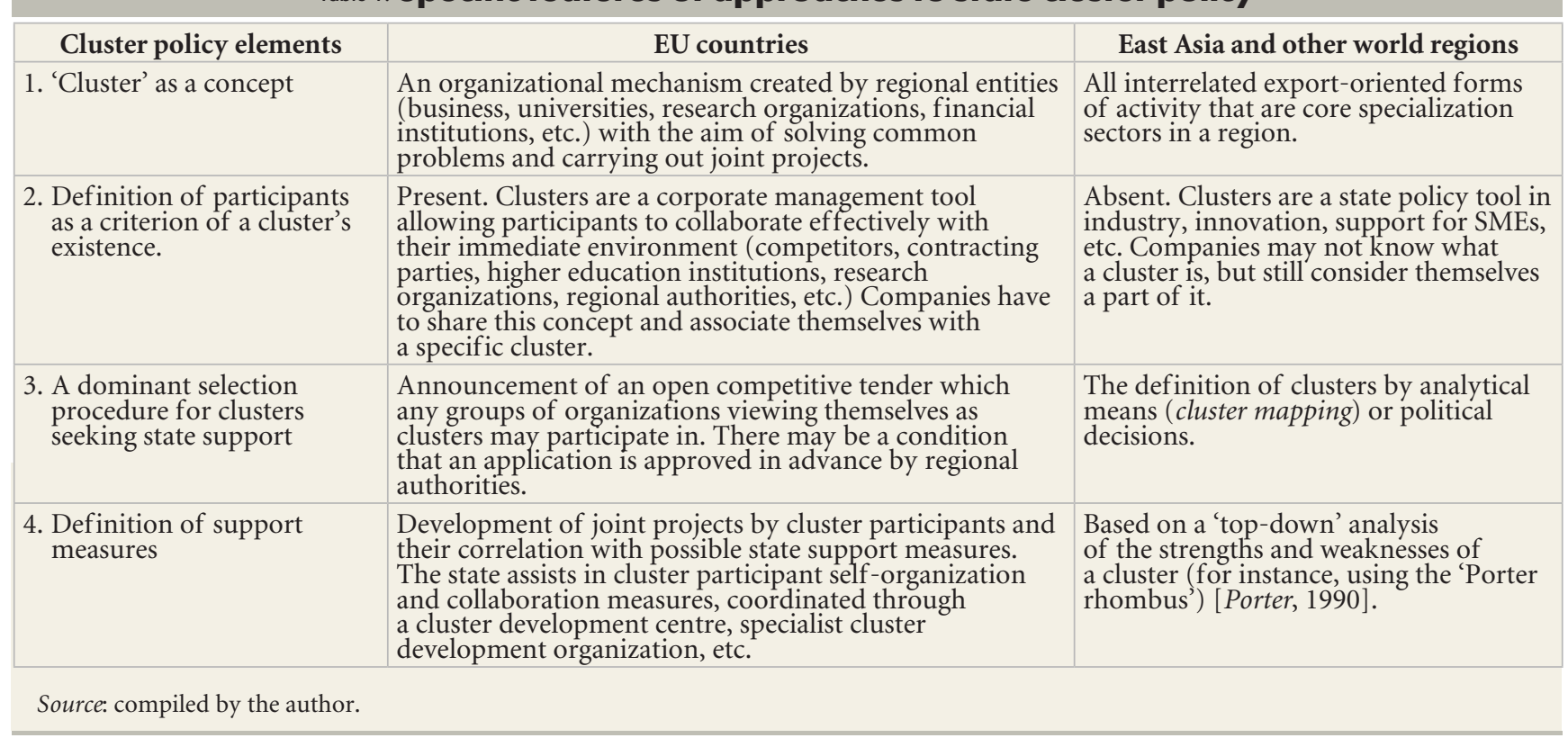

356 clusters took part in the 'Cluster Initiative Greenbook 2.0' study, of which 254 were European [Lindqvist et al., 2013, pp. 11, 13]. 
Denmark, Spain, Italy, the Netherlands, Norway, Poland, Portugal, Slovenia, Finland, France, the Czech Republic, and Sweden. It resulted in a collection of best practices for stimulating user-driven innovations in clusters, the use of the cluster approach to develop emerging industries, cluster marketing and branding, assessing the effects of cluster policy, and international collaboration, among other things.

Over the last decade, the core literature on cluster policy has been enriched with qualitative studies. As such, the European Cluster Observatory, guided by Michael Porter's methodology [Porter, 2003], carried out a statistical analysis covering all European countries with a view to uncovering clusters. The resultant database then served as a basis for subsequent studies, including those at the request of the European Commission [European Commission, 2007]. The Observatory also keeps a pan-European register of specialist cluster organizations. In its 'Innobarometer' report for 2006, it assessed the impact of such structures on innovation processes [European Commission, 2006].

Another influential international project was the Global Cluster Initiative Survey. It resulted in two 'golden books' [Sölvell et al., 2003; Lindqvist et al., 2013] presenting analytical material on 238 and 356 clusters respectively, although this only accounted for $10-15 \%$ of the total number of clusters identified on a global scale.

The comparative study 'Clusters are individuals' is noteworthy, covering 230 specialist cluster organizations and state support programmes in 23 European countries. It set out best practices, support programmes and key success factors [Müller et al., 2012] and made recommendations for the future [Christensen et al., 2012].

The format of recommendations for European politicians and managers is not new. One of the first guides of this type presented successful, leading experience from cluster development in the region of Upper Austria [CLOE, 2004]. The report 'Clusters and clustering policy: a guide for regional and local policy makers' [INNO Germany AG, 2010] summarized the views of a number of EU, UNIDO and OECD experts, as well as representatives of national and regional governments and cluster managers. The conclusions of the latest empirical studies are summarized in the work [Ketels, 2013].

The European Cluster Excellence Initiative's system of assessing the quality of cluster management ${ }^{2}$ is a perfect example of accumulated experience, serving as a basis for the certification of almost one third of managing organizations [Müller et al., 2012]. In view of the current European interpretation of clusters as an organizational mechanism (Table 1), the studies mentioned here do not touch on the economic parameters of their operations, such as their combined revenue, investment, and research and development (R\&D) expenditure. The focus is instead placed on the various aspects of collaborations between participants. The more significant facts and figures include the number and make-up of participants; the life span, field of activity, sources of funding, organizational structure and staff numbers of specialist cluster organizations; and the mechanisms to take into account the different interests (primarily of business and state authorities) in their activities. In essence, it is not the cluster as a group of actors that is assessed, but rather the quality of the cluster initiative, i.e., the organizational efforts to support the cluster.

In Russia, a vast collection of scientific literature has been amassed on this topic but the standard lags far behind that of foreign studies. This is primarily due to the lack of detailed information, which started to become available only relatively recently for cluster support programmes. ${ }^{3}$ In the majority of cases, publications relate to specific examples, while comparative works are extremely few

Available at: http://www.cluster-excellence.eu/, accessed 18.12.2014

In addition to the aforementioned pilot innovation clusters, in some Russian regions, support is being offered to cluster development centres. From 2010, as part of a small and medium enterprise development programme, the Russian Ministry of Economic Development allocated subsidies for this purpose amounting to a total of almost 650 million roubles. Funding was received in: Saint Petersburg, Astrakhan, Belgorod, Voronezh, Irkutsk, Kaluga, Kemerovo, Kirov, Kurgan, Lipetsk, Murmansk, Novgorod, Penza, Rostov, Samara, Tomsk, Tambov and Ulyanovsk regions (oblasts); Kalmykia, Sakha (Yakutia), Tatarstan and Altai regions (republics); Stavropol and Khabarovsk regions (krais), and the region of Khanty-Mansi Autonomous Okrug (Yugra). 
in number. ${ }^{4}$ Recommendations are of ten not adapted to Russian conditions and directly copy foreign practices; however, it remains frequently unclear what exactly are the main shortcomings of national clusters and which of the proposed measures are of greatest interest.

Statistics on Russian clusters started to expand significantly from the launch of a pilot innovation clusters competition in 2012, as part of which applicants prepared fairly comprehensive applications (a total of 94), including a development programme..$^{5}$ In 2013, participants in the first group (excluding the Medical and Pharmaceutical Industry and Radiation Technologies Cluster of Saint Petersburg) submitted further applications to the Russian Ministry of Economic Development to receive a federal subsidy to fund specific measures.

All of these materials lay the foundation for a more in-depth study of Russian clusters. It is worth mentioning the 2014 joint study by HSE and the statistical development centre 'Severo-Zapad' at the request of the state corporation Russian Venture Capital, or OAO RVK [RVK et al., 2014]. This study circulated questionnaires to all pilot clusters in Russia (and received 17 completed questionnaires) and held workshops with them.

The publication of new information opens up opportunities for proper crosscountry comparison of cluster development trends and drafting of expert recommendations. Of course, many aspects analysed in foreign studies lack equivalents in Russia, where cluster initiatives are still in their early stages. At the same time, a number of problems have already emerged, knowledge of which makes it possible to outline areas of improvement in cluster policy.

In our study, we are proceeding from the premise that stable cluster development is shaped by three groups of factors:

- the external environment and composition of participants;

- the closeness of communications and the level of self-organization;

- companies and universities that make up a cluster are strategically geared towards innovation.

We will now look in more detail at each of these conditions in view of the current realities characteristic of Russian pilot clusters today.

\section{Environment and participants}

A developed urban environment, a critical mass of core companies, the dominance of private initiatives, domestic competition, and an openness to the outside world are among the basic conditions exerting a significant influence on the formation of clusters and their future prospects.

\section{Developed urban environment}

Clusters are highly sensitive to the dynamics of an urban environment which is attractive to qualified workers (including members of the creative class ${ }^{6}$ ) and offers favourable conditions for innovative business undertakings. It presupposes a high level of diversity in professions and skills, a developed infrastructure, and a strong academic component.

Some Russian pilot clusters are situated in single-specialism cities ${ }^{7}$, and a number of these are classified as closed cities ('closed administrative territorial formations' or ZATO). During Soviet times, these places were renowned for their high

\footnotetext{
${ }^{4}$ Some exceptions include the 'Pilot innovation regional clusters in the Russian Federation' [HSE, 2013], a study by [Golovanova et al., 2010], the empirical basis of which was an interview based on a questionnaire with content similar to the 'Innobarometer' methodology [European Commission, 2006] and the article by [Abashkin et al. 2012] which contained recommendations to improve the Russian federal support programme for pilot clusters when it started in 2012.

A list of applications is provided in Appendix 4 of the report [HSE, 2013]. Pilot cluster development programmes are listed on the Russian Cluster Observatory website (available at: http://cluster.hse.ru/clusters/, accessed 24.01.2015).

${ }^{6}$ One of the authors behind the creative class concept, Richard Florida, values its development in terms of its ability to calculate the so-called creative industries' contribution to overall employment. Creative industries are taken to mean programming, mathematics, architecture, engineering, natural and social sciences, education, training, library services, art, design, entertainment, sport, media, management, business and finance, law, health care, and trade [Florida, 2002].

This refers largely to the Innovative Technologies Cluster in the Zheleznogorsk closed city (ZATO), the Sarov Innovation Cluster, the Shipbuilding Innovative Regional Cluster in Arkhangelsk Oblast, and the Nuclear Innovation Cluster in Dimitrovgrad, Ulyanovsk Oblast.
} 
quality of life, but today they often lag behind regional centres in this regard, which leads to an outflow of qualified workers. In this context, the development of clusters is held back by factors such as the dominance of large enterprises (often those that created the entire city), the fixation of a particular specialism in a city, and an orientation towards public contractors.

Consequently, in such cases the problem of attracting and retaining highly qualified professionals from scientific and business circles, managers, and venture capitalists arises. For this, experience shows that it is important to implement several measures to serve as a basis for cluster policy:

- create jobs characterized by high productivity and wages compared with regional centres;

- expand economic specialization, career opportunities and growth in interfirm mobility within the city;

- establish mortgages, preferential lease mechanisms and residential buying schemes for cluster business workers and expand modern low-rise and villa developments;

- develop food, leisure and cultural infrastructure;

- implement green technologies, improve ecology, make good use of advantages such as closeness to nature, healthy lifestyles, lack of traffic, etc.

We note that it is rare for these aspects to be given serious attention in cluster development programmes. One of the striking exceptions to this is the Dimitrovgrad Nuclear Innovation Cluster, which has initiated projects to establish a library-based modern intellectual centre, form a network of general educational organizations offering international baccalaureate programmes, and modernize the local stadium.

\section{Critical mass of core companies}

The more companies in a cluster that engage in core, associated or supporting forms of activity and involve corresponding specialists, the more likely it is that innovations will result and spread. This can be explained by the fact that geographical concentration helps to speed up how information is distributed between enterprises, exchange ideas, and brings to light new knowledge and products, including through new combinations of existing knowledge and products. ${ }^{8}$

Based on European experience, to achieve the required potential a cluster has to include at least 30-50 organizations [CLOE, 2004] or, according to some estimates, as many as 100 [Pamminger, 2014]. A global survey of 356 clusters carried out in 2012 showed that, on average, a single cluster brought together 80 participants [Lindqvist et al., 2013, p. 17]. In Russia the average number of organizations in pilot clusters is $44^{9}$, which is almost half the global average. Out of 25 clusters, only two have more than 100 members, ${ }^{10}$ and a number of others have fewer than 20 .

Out of the six industrial fields under which Russian pilot clusters can be classified [HSE, 2013], the largest number of of ficial participants on average was seen in the information and communication technology (ICT) and electronics industry, as well as the pharmaceuticals, biotechnology and medical industry (Figure 1). Such inequality, it would seem, is linked to the fact that innovative small and medium enterprises (SMEs) undergo active development in these fields and as a result, the overall number of firms increases. In addition, these

\footnotetext{
8 According to Jared Diamond, the history of technology is a self-catalysed process, stimulating itself and accelerating over time [Diamond, 1997]. It is not passed on in a uniform way, and to a large degree gravitates towards clusters where there is the necessary critical mass of participants.

${ }_{9}$ Including regional authorities and local government bodies, educational and research organizations, financial sector institutions and public development institutes. Pilot innovation cluster development programmes approved by regional administrations in 2013 and submitted to the Russian Ministry of Economic Development for federal subsidies were used for this calculation. If these programmes were not taken any further (for clusters in the second group) or there was no list of participants, information was taken from pilot cluster development programmes in 2012. Information on clusters in Saint Petersburg and Leningrad Oblast was taken from 2012 programmes without taking into account their subsequent merger.

${ }^{10}$ The number of information technology cluster members in Tomsk Oblast was originally 131 organizations. However, after it became a part of the 'Pharmaceuticals, medical technology and information technology' unified cluster in 2013, the number of participants fell to 61.
} 
Figure 1. Average number of official pilot innovation regional clusters in Russia by industry (units)

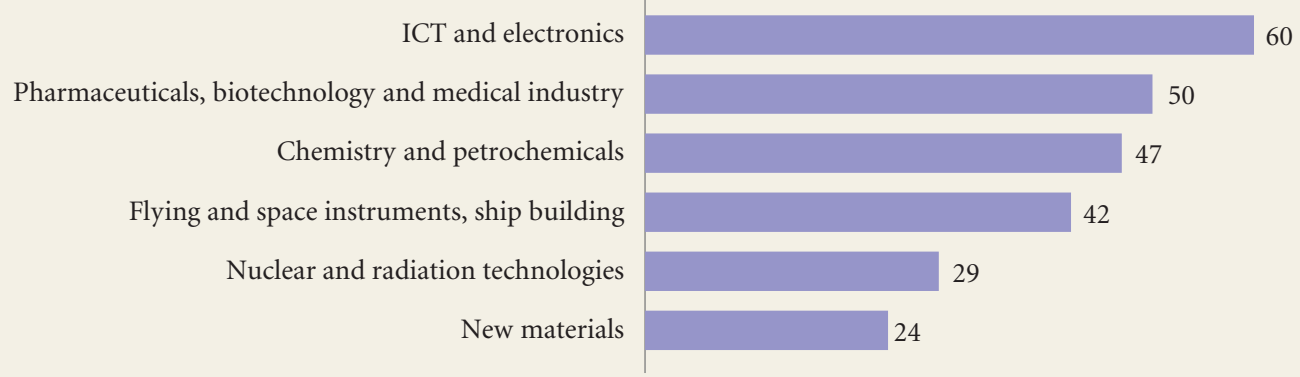

Source: author's calculations based on survey data from pilot innovation regional clusters.

sectors are the most sensitive to cluster formation processes, in particular in the ICT sphere, which leads the way in terms of the total number of clusters globally (Figure 2).

The far from optimal pool of core enterprises in Russian clusters is having a negative impact on the number and quality of new projects. Without a focus on supporting them, clustering only intensifies the status quo in the region's economy and risks becoming an instrument for lobbying rather than innovative development.

It is worth bearing in mind that the number of similar companies in a region, in terms of their core business, should exceed the official number of members of a cluster. The reason for this is that, clearly, not all businesses are prepared to join the cluster. A cluster is primarily of interest to those receptive to the advantages of carrying out joint projects and using common services, strategically geared towards open innovations.

The relative size of clusters is also of considerable importance. In any given region, it is reasonable to support those clusters which operate in sectors that exceed the average level for the country by twice or more in terms of their economic indicators (number of employees, total revenue, export volume, R\&D intensity). A gap between the current objective directions of a regional specialization and the core activity of supported clusters is also linked to risks. Such alliances can experience a shortage of resources for development (skilled workers, infrastructure, suppliers, or research provision). Moreover, support for them may not have any significant impact on the region's social and economic development. There is a lingering fear that if such clusters are picked by federal authorities, they will not become a priority for the regional administrations. This was the

\section{Figure 2. Global distribution of clusters by specialization field (units)}

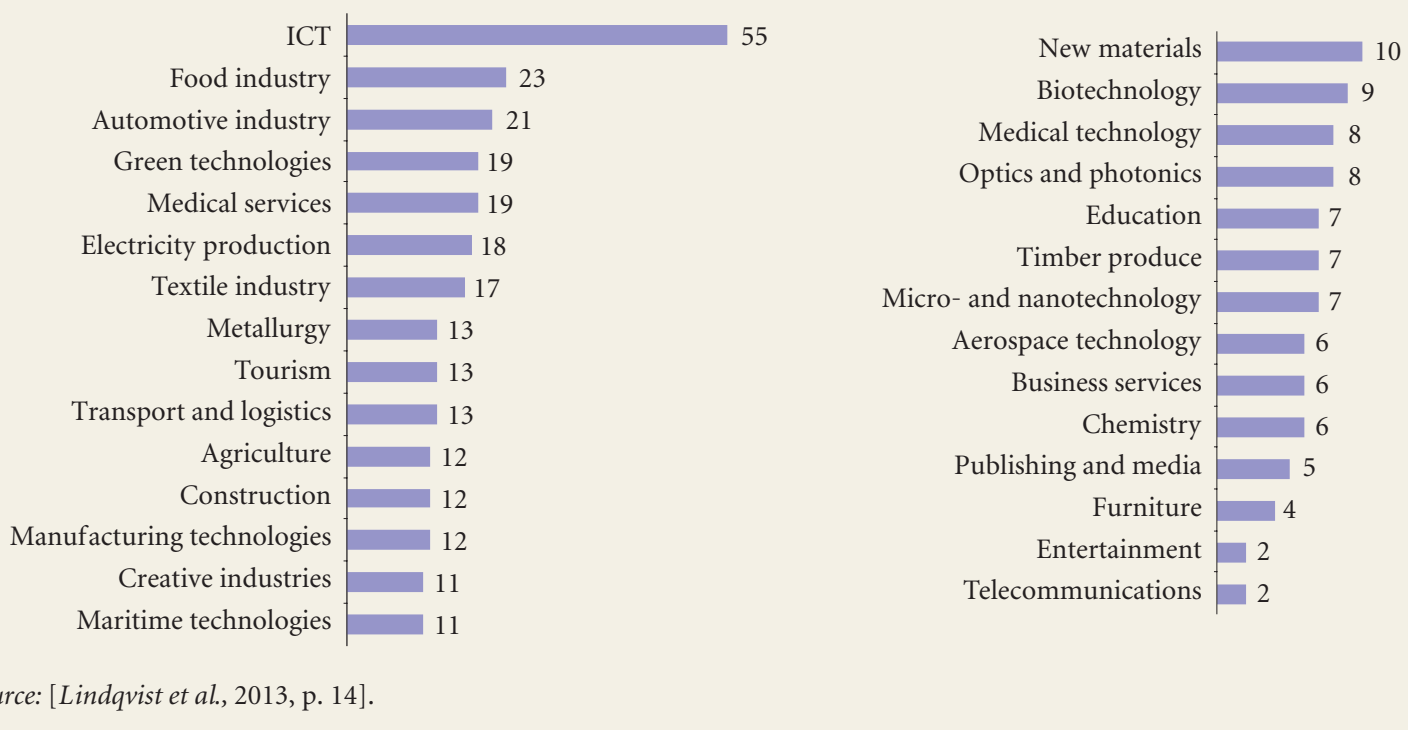


case, for example, in the Moscow region, the city of Saint Petersburg, and the nuclear technology clusters in the Nizhny Novgorod and Ulyanovsk regions. ${ }^{11}$

\section{Dominance of private initiatives}

A private initiative is a decisive factor in the success of a cluster. Even in cases when successful clusters established on the back of a university or a research centre encompass a large number of diverse entities (Figure 3), without enterprises playing a leading role they do not have any serious prospects. According to experts, stable cluster development comes from the prevalence of members of the business community in the upper echelons of the administration [INNO Germany AG, 2010, p. 108]. Therefore, the European system of assessing the quality of cluster management is based, among other things, on the proportion of manufacturing and service companies in the total number of participants, and this proportion must be greater than 50\% [Hagenauer et al., 2012, p. 2].

At least ten Russian pilot clusters do not meet this criterion. ${ }^{12}$ In many Russian clusters, publicly owned companies tend to dominate, alongside their subsidiaries and dependent organizations, state educational and research institutions, and regional authorities. There is a clear deficit of private sector initiatives, which serves as an indicator of the essential nature and effectiveness of clusters, including investment rationality, internal relations quality and project investment appeal. The role of business only increases if a cluster initiative arose as a result of a state-organized competitive tender with corresponding support measures.

From 2013, there has been a sharp rise in the influence of regional administrations on management entities in pilot clusters. In the overwhelming majority of cases, they were the founders of specialist organizations created to coordinate

\section{Figure 3. Initiators of pilot innovation regional cluster creation}

Ulyanovsk-Avia research, education and manufacturing cluster consortium

Innovative Rocket Propulsion Regiona Cluster 'New Star' Technopolis

Sarov Innovative Cluster

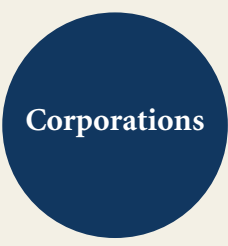

Innovative regional radio electronics, device manufacture, communications and info-telecommunications cluster, Saint Petersburg

Source: compiled by the author.

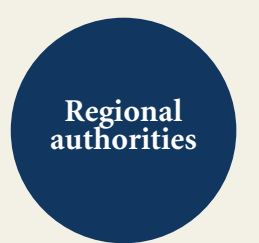

Energy efficient lighting technology and smart lighting control systems (Republic of Mordovia)

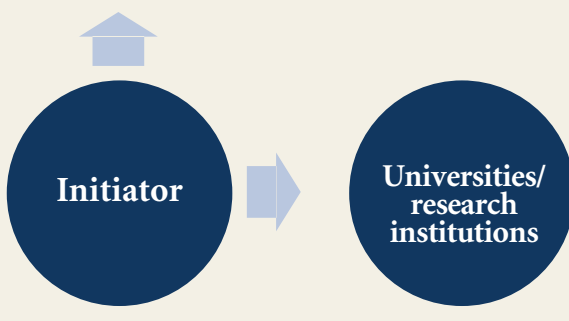

Phystech XXI cluster



Biotechnology innovation regional cluster Pushchino

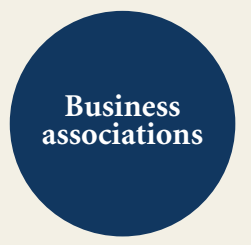

Innovative regional information and

telecommunications technologies cluster Novosibirsk Oblast 'SibAkademSoft'

\footnotetext{
${ }^{11}$ Federal subsidies are provided on the condition that they are jointly funded by regional authorities; extrabudgetary funds are not taken into account. This often creates tension, as receiving federal support starts to depend not on the activities of the local community and the quality of the projects prepared but more on the success of negotiations with regional administrations. Sometimes, the edge in the negotiation process starts to become part of the public domain [Vikulova, 2013; Sarov.Net, 2014].

${ }^{12}$ The Innovative Technologies Cluster in the Zheleznogorsk closed city (ZATO) (Krasnoyarsk Krai), Nuclear Innovation Cluster in Dimitrovgrad (Ulyanovsk Oblast), Radiation Technologies Cluster (Saint Petersburg and Leningrad Oblast), Shipbuilding Innovative Regional Cluster (Arkhangelsk Oblast), Innovative Rocket Propulsion Regional Cluster 'New Star' Technopolis (Perm Krai), Aerospace Cluster (Samara Oblast), Pharmaceutical, Biotechnology and Biomedicine Cluster (Kaluga Oblast), Biopharmaceutical Cluster (Novosibirsk Oblast), Petrochemical Regional Cluster (Republic of Bashkortostan), and Kamsk Innovation Regional Manufacturing Cluster (Republic of Tatarstan). The subsequent fusion of certain clusters was not taken into account, as not all merged clusters had data on the number and structure of participants. Some clusters were excluded from the calculation, as their programmes did not contain detailed information on participants.
} 


\section{Figure 4. Distribution of specialist organizations in pilot innovation regional clusters by Status (\%)}

Regional development institute (development corporation, agency, etc.)

Cluster development centre set up as part of a small and medium enterprise support programme

Innovative development department in a corporation

Technology park

Regional development institute and cluster development centre

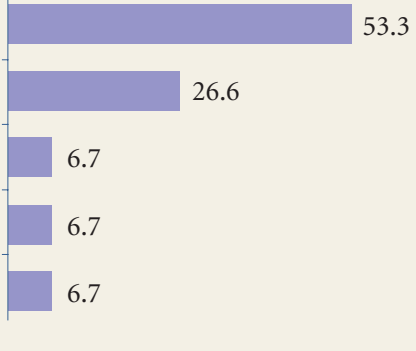

Source: author's calculations based on survey data from pilot innovation regional clusters.

collaboration between participants, carry out joint projects, etc. ${ }^{13}$ Roughly half of these organizations were formed (or designated) as a superstructure over the top of existing administrative bodies (Figure 4).

Although regional authorities are also dependent on established rules [Government of the Russian Federation, 2013], in a number of locations the situation is one of 'dual rule.' This applies, in particular, to clusters in Moscow city and Moscow, Tomsk and Novosibirsk regions. This can weaken the legitimacy of official specialist organizations, cause disagreements and further destabilize partnerships.

The only means by which members can influence a specialist cluster organization is in a general assembly of participants (Figure 5). However, the status of this is more of a formality and is ineffective when it comes to decision making

\section{Figure 5. Mechanisms to take into account private and state interests in the activities of specialist pilot innovation regional cluster organizations (distribution by number of practising clusters, units)*}

\section{Of which:}

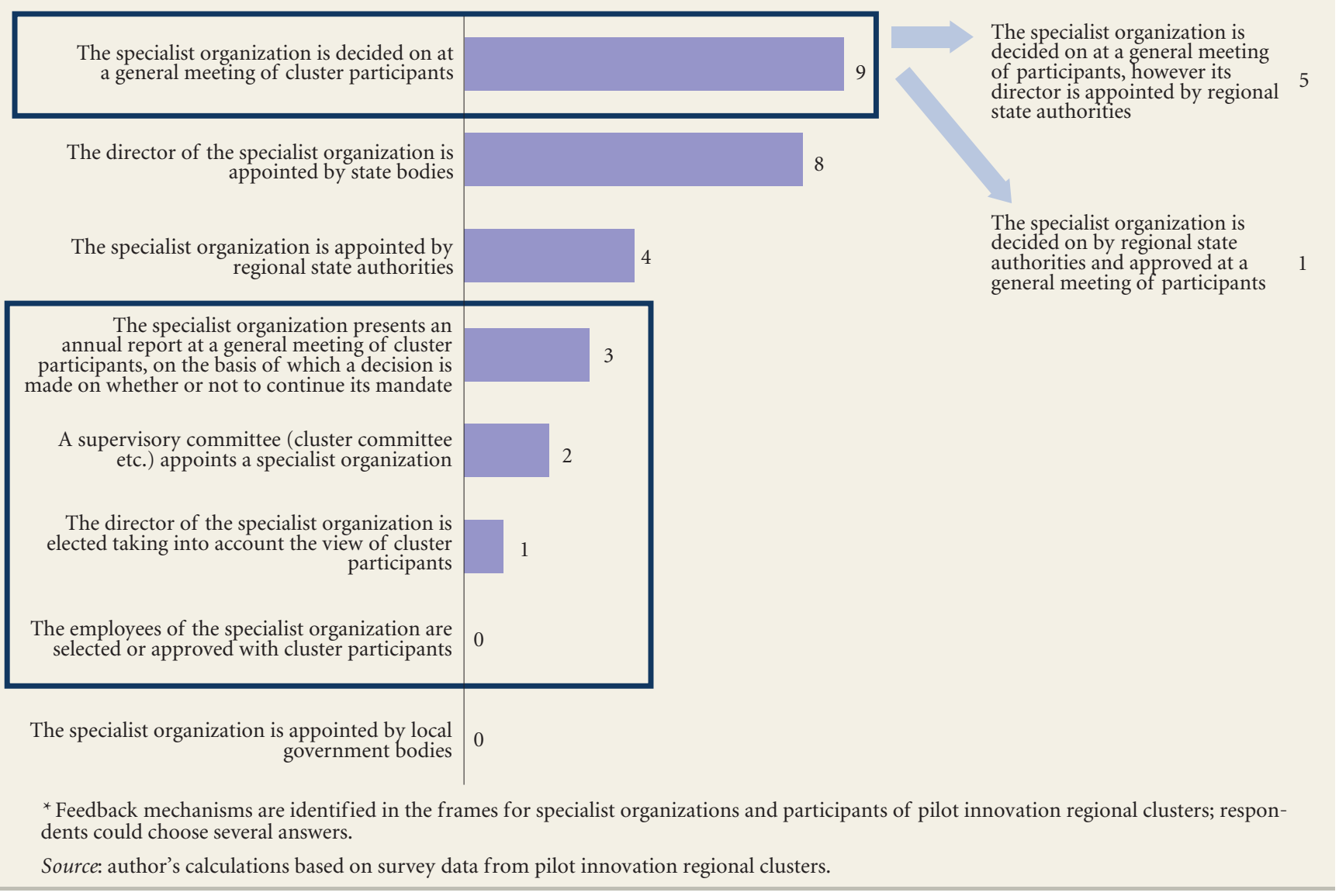

\footnotetext{
${ }^{13}$ A distinction needs to be drawn between a specialist cluster organization and a cluster committee and other forms of higher collective executive bodies functioning on a gratuitous basis. A specialist organization is an operational management entity which has employees whose main duty is to develop a cluster. These employees are personally responsible for the specific directions in which a cluster develops, how its projects are carried out, etc.
} 
Figure 6. Composition of supervisory boards at specialist cluster organizations globally (\%)

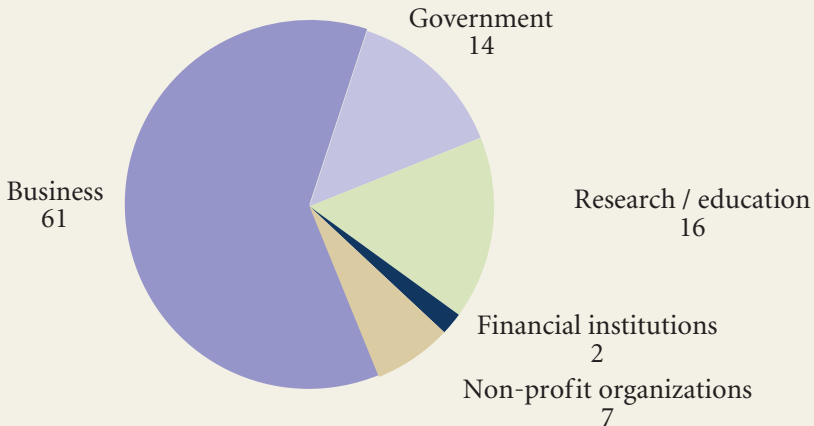

Source: [Lindqvist et al., 2013].

on operational matters. Thus, the views of cluster participants and higher collective managerial bodies (supervisory board, etc.) are rarely taken into account when appointing managers and other employees at specialist organizations.

The international study cited above revealed the opposite situation: the share of the private sector in the higher managerial bodies of clusters to which the executive director of a specialist organization is accountable is more than half. In other words, the stance of this category of participants is decisive [Lindqvist et al., 2013] (Figure 6).

The dominance of the state in the management of Russian clusters is reinforced by its status as the main source of funding (Figure 7).

The poorly developed mechanism for payment of annual membership contributions is a sign of the weak influence of cluster members on the activities of specialist organizations. ${ }^{14}$ In other countries besides Russia , as shown in Figure 8, the funding structure is more diversified: the largest share of private funds comes from membership contributions and the remainder from additional paid services (project management, seminars, etc.).

One of the key criteria underlying the influence of the business community is the share of SMEs in the total number of cluster participants. Under the socalled European model, they usually dominate and are the main beneficiaries of state support [Dohse, Staehler, 2008; Eickelpasch, 2008; DGCIS et al., 2012; Pro Inno Europe, 2009; Christensen et al., 2012, p. 10].

Figures for SMEs were included in Russia's pilot cluster selection criteria system. It transpired that the share of such companies in total participant numbers lags far behind European levels (Figure 9). The highest value seen was in ICT clusters; however, if this figure is ignored, the proportion of such entities falls from $34 \%$ to $19 \%$. Furthermore, being a participant, technically speaking, does not imply a real contribution to state funded joint projects. An analysis of programmes submitted to the Russian Ministry of Economic Development in 2012 shows

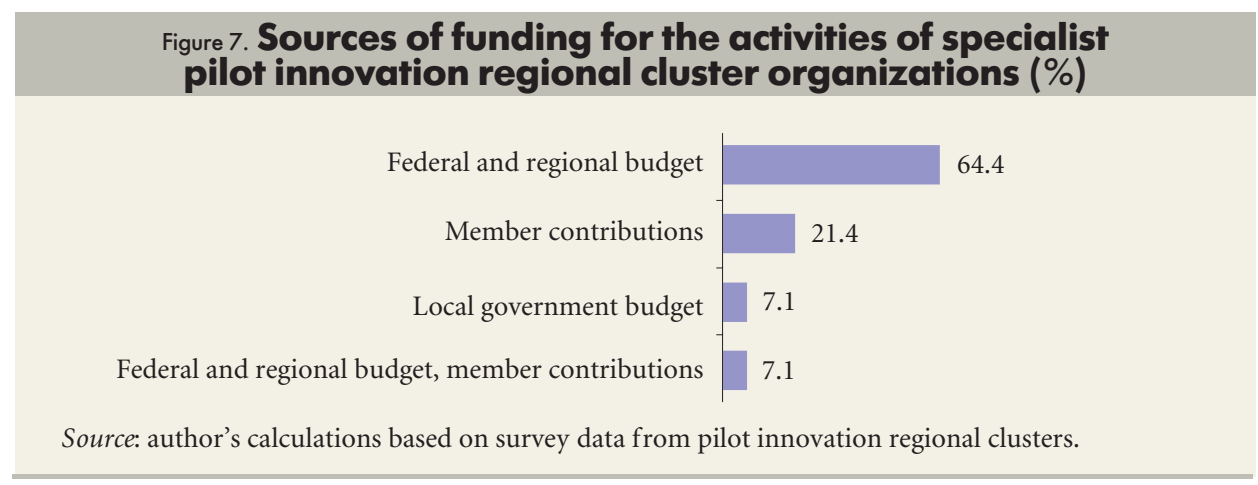

${ }^{14}$ Out of the four respondents noting membership contributions as a source of budget replenishment, two - the non-profit organizations BFKS and Sibakademsoft - are not de jure specialist organizations in their clusters. In the other two cases, Dubna (the Nuclear Physics and Nanotechnology Cluster in Dubna) and Kamsk Innovation Regional Manufacturing Cluster (Republic of Tatarstan) are classified as non-profit partnerships. At the same time, there is no information on whether the stipulated membership contributions are actually collected and what share they account for in the budget structure of specialist organizations. 
Figure 8. Funding structure of specialist cluster organizations globally $(\%)$



that in the majority of cases, there are few or no projects initiated by SMEs. In reality, major companies and state authorities dominate in Russian clusters.

\section{Internal competition and openness}

The existence of a sufficient number of companies from inter-related sectors in a cluster is a significant factor for the cluster's future sustainability but competition is also needed. Competition within the cluster stimulates improvement, contributes to the flow of human and financial capital, and attracts the most dynamic and pushes out the least effective entities as a result of the growing cost of immobile factors of production. It is important to ensure that there is competition between companies in a cluster. Rivalry with outside actors, including foreign companies, is not enough because this competition is not very intense. There are several objective reasons for this: differences in the cost of production factors, tax regimes, and the difficulty in benchmarking competitors. Localized competition is also stirred up by a desire not to lose to a well-known neighbour [Porter, 1998].

Building on Porter's thesis, we posit that internal competition between businesses is particularly important when trying to implement an innovation scenario.

\section{Figure 9. Proportion of various categories of cluster participants in EU countries and Russia (\%)}

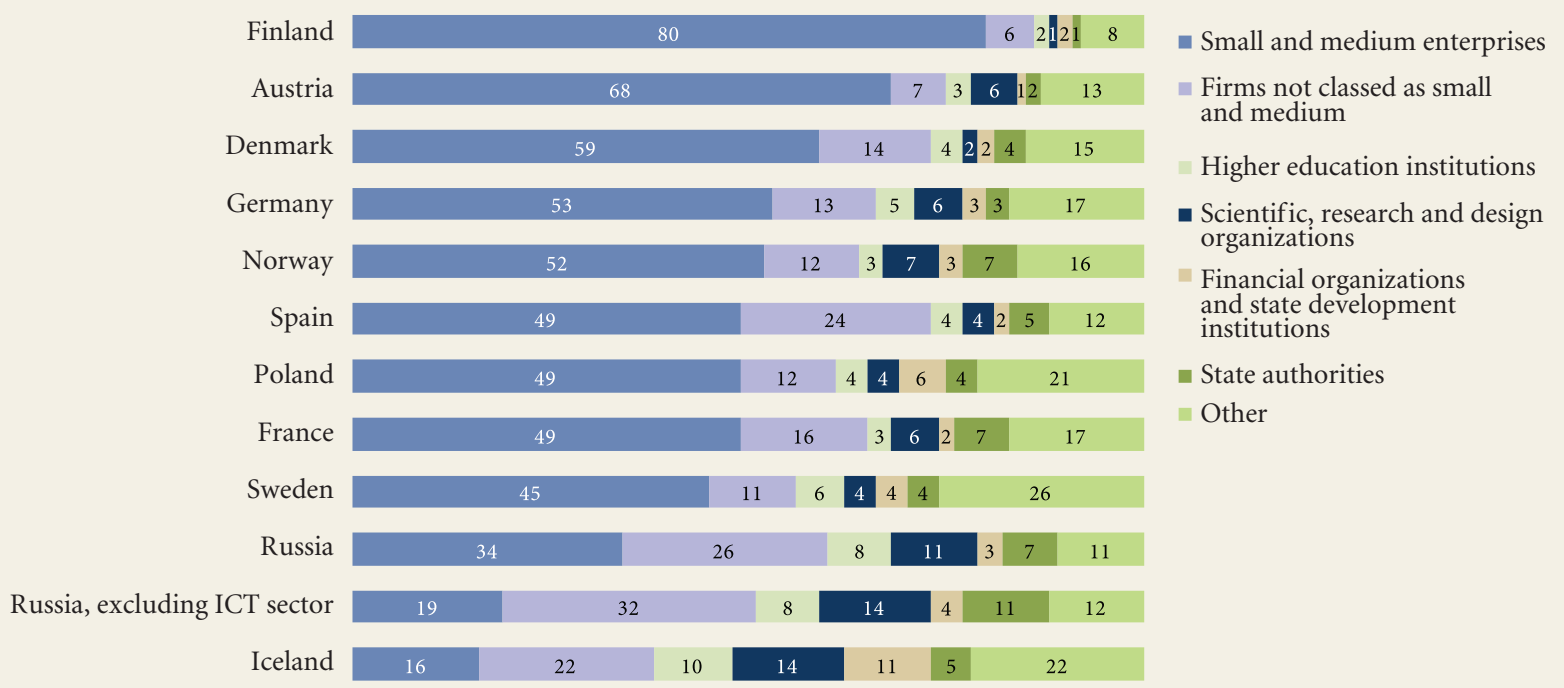

Source: author's calculations based on data from [Müller et al., 2012, p. 18] and pilot innovation regional cluster development programmes*

* The information base for the calculations was compiled from pilot innovation regional cluster development programmes submitted to the Russian Ministry of Economic Development in 2012. As such, the subsequent merger of a number of clusters has not been taken into account. Clusters whose programmes did not contain information on the number of participating small and medium enterprises were not included: The UlyanovskAvia research, education and manufacturing cluster consortium (Ulyanovsk Oblast), the Biotechnology Innovation Regional Cluster Pushchino (Moscow Oblast), the Pharmaceutical and Medical Industry Cluster (Saint Petersburg and Leningrad Oblast), Pharmaceuticals and Medical Technology (Tomsk Oblast), New Materials, Laser and Radiation Technologies (Troitsk, Moscow), Complex Coal and Man-made Waste Processing (Kemerovo Oblast), the Nizhny Novgorod Industrial Innovation Cluster for Automobile Construction and Petrochemicals (Nizhny Novgorod Oblast), and Energy Efficient Lighting and Smart Lighting Control Systems (Republic of Mordovia). The sample covered a total of 21 clusters. 
Innovations are developed more effectively if the competitive battle is fought on equal economic, social and legal grounds and unfair conduct is suppressed by the state. Fundamental differences in the environment in which competing players are situated bring to the fore such weapons as state political and military establishment involvement, attempts to financially win over or exert pressure on government of ficials, deals and market division, among others.

Geographical concentration, as a general rule, assures greater equality in the environmental conditions in which the competition takes place, which increases the economic viability of an innovative competition scenario. Unfortunately, in the absolute majority of cases, domestic clusters see internal competition as an undesirable factor. The exceptions are the ICT, biotechnology and pharmaceutical sectors.

A mistaken yet widespread view supposes that building a model with a single large enterprise surrounded by suppliers or localizing the value-added chain is sufficient to form a cluster. However, the localization and distribution of valueadded chains, as well as the question of outsourcing, are not the only (or the main) objectives of cluster policy. Quite often, state interference leads to the opposite result: 'forced' localization, imposed contracting parties, and shaping the value-added chain 'from above' all risk turning into losses and general ineffectiveness. We note that clusters can evolve dynamically and without a single value-added chain (something characteristic, for example, of the tourism or ICT sectors). However, without developed internal competition, progress will hardly be sustainable in the long-term.

\section{Closeness of communications and self-organization}

Innovations tend to arise in open, flexible communities with low power distances and a large number of communications running between representatives of various social (including professional) groups. Therefore, a sustainable cluster presupposes intensive communications not only between organizations, but also between individual specialists irrespective of their affiliation. Together with the presence of a critical mass of core companies and human resources, this is an important prerequisite to set in motion a self-catalyzing innovation process [DTI, 2004, p. 22].

One of the basic conditions for effective communications is a high degree of trust [INNO Germany AG, 2010, p. 41]. Despite the fact that this is closely linked to culture and any changes are throwbacks to former inertia, the implementation of cluster policy requires a constructive examination of this phenomenon. To forge trust in a purposeful manner, a whole set of instruments can be put forward, including [Hwang, Horowitt, 2012]:

- work by 'key figures' or organizations - 'trust guides' — who are capable of establishing useful links;

- special programmes to study behaviour patterns in role models and pilot projects and their approval in real life;

- development of common collaboration standards;

- designing feedback systems.

These instruments are entirely appropriate for raising trust and, consequently, developing internal communications in Russian clusters.

\section{Specialist independent management bodies}

These 'key figures' and organizations capable of establishing productive links refer to cluster managers and specialist management bodies. The first of these structures appeared in the 1990s in Austria, Germany and Finland, and later in Denmark, France, Norway, Sweden, Spain, Poland and Iceland [Müller et al., 2012, p. 14]. They help to coordinate the visions, goals and strategies of participants and improve the closeness of internal communications, organize collaboration with state authorities, development institutes, publicly owned companies, other clusters, etc., and act as representatives in external measures (Figure 10).

Today, the need for institutionalization by creating specialist organizations is viewed as a significant step towards cluster development and is virtually beyond doubt [INNO Germany AG, 2010, pp. 107, 111]. The importance of state 


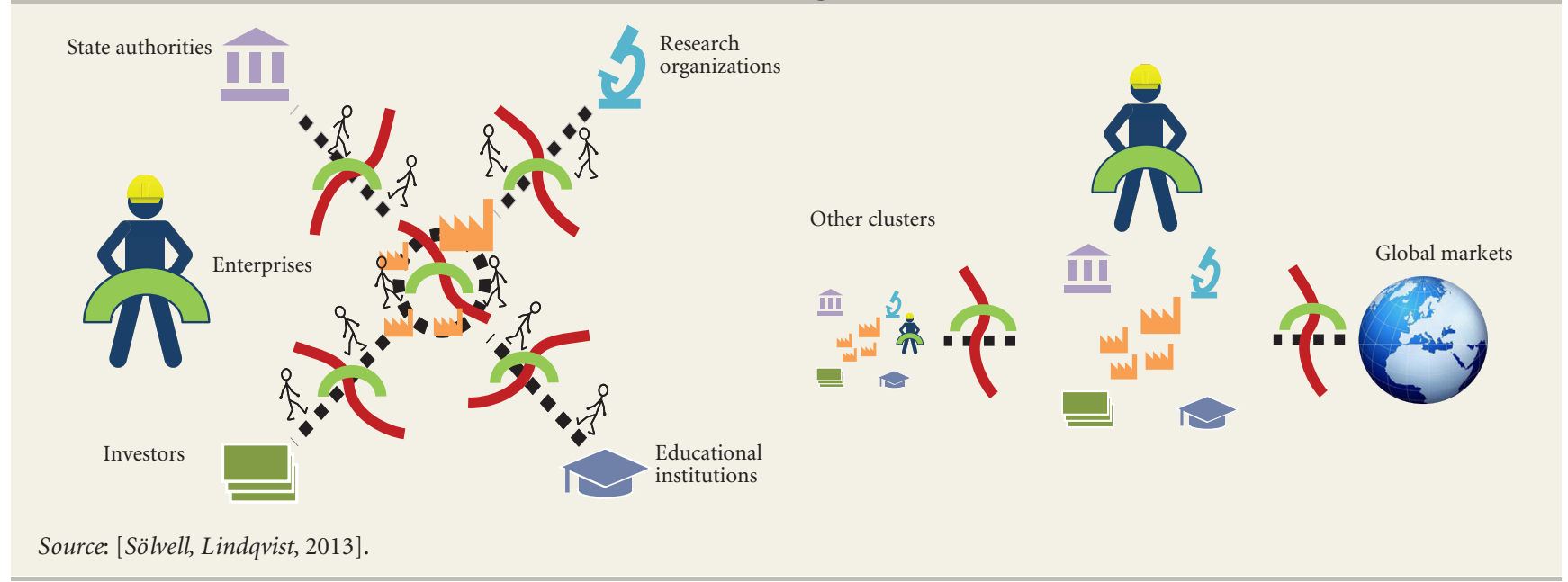

funding for such structures, at least for the first few years, is shown by the lack of trust between participants [Ibid., p. 42]. It was initially assumed that specialist organizations should be supported for three to a maximum of six years, after which they should be able to self-fund or close [CLOE, 2004]. Practice however has changed this view. It transpired that even successful associations (such as the Upper Austria automotive cluster) required support from the state and the EU over a decade in order to reach a stage of sustainable self-funding. In view of the long time lag for any results to become visible, the recommendation is that they are first assessed no sooner than five years after the start of funding. Therefore, stable support for specialist organizations and cluster development centres is becoming an important condition underpinning the success of state policy. Shortterm cluster initiatives are doomed to failure, and it is wrong to require them to transition to a commercial basis after only several years of budgetary funding [INNO Germany AG, 2010, pp. 116, 118, 130, 135].

A more radical position argues that support for clusters should be constant and not project-based, since such structures carry out a number of social functions [Ibid., p. 117]. A recent study showed that over the course of roughly the last ten years, the share of state funding for clusters stabilized at a minimum of $60 \%$ [Lindqvist et al., 2013, p. 5].

In this case, the practice in Russian clusters is consistent with theory. Providing for the activities of specialist organizations has come to be one of the possible measures to develop a pilot cluster applying for federal subsidies. This approach was used by virtually all entities in the first group, which formed specialist organizations with a staff and an operational plan. ${ }^{15}$ The average number of staff at these organizations is eight people, ranging from two to $23 .^{16}$

A survey of 17 of the 25 pilot clusters in Russia carried out at the end of 2013 revealed the most pressing activities of specialist organizations:

- intensifying collaboration between participants to develop and implement joint projects aimed at raising competitiveness;

- setting up joint scientific, research, design and experimental projects between participants and external partners;

- developing joint innovation projects.

One of the key roles of specialist organizations is training. In the first stages of cluster development, programmes to raise qualification levels not only perform

\footnotetext{
${ }^{15}$ The exception to this were clusters in Moscow Oblast (the Nuclear Physics and Nanotechnology Innovative Regional Cluster in Dubna, the Biotechnology Innovation Regional Cluster Pushchino, and the Phystech XXI cluster). The region's government did not request any federal subsidies at the first stage (and, in all likelihood, did not plan to jointly fund subsidies from the regional budget) for specialist organizations to implement measures to develop pilot clusters.

${ }^{16}$ The maximum staff numbers was declared by a specialist pilot cluster organization which is at the same time a regional cluster development centre. The distinguishing feature of this organization is that it has been recognized as contributing to the development of several or even all of the clusters in the region. As such, it can be assumed that the number of staff directly involved in the development of a pilot cluster is less than the total number of workers at the cluster development centre.
} 


\section{Figure 11. Importance of various types of collaboration in clusters from the viewpoint} of the activity priorities of their specialist organizations (\%)

\section{EU countries}

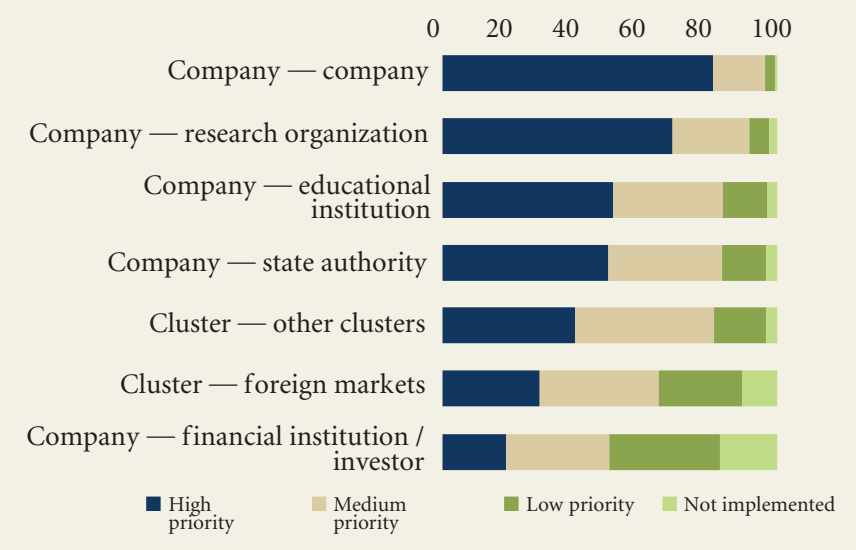

Russia

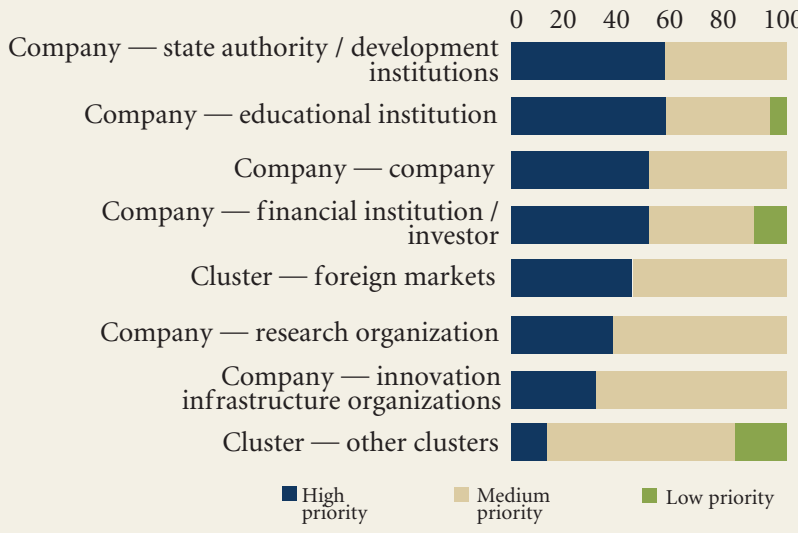

Source: [Sölvell, Lindqvist, 2013]; author's calculations based on survey data from pilot innovation regional clusters in Russia.

an educational role, but also play the role of a joint project contributing to the establishment of contacts between employees in different organizations, the formation of interest groups, and the identification of potential areas for collaboration. Specialist measures (strategic sessions) that aim to help cluster participants agree on goals and strategies, search for shared interests, and develop joint projects are extremely beneficial.

Professional retraining, raising qualifications and arranging training were all identified as areas for potential use of federal subsidies by clusters in the first group in 2013 [Government of the Russian Federation, 2013]. Virtually all applicants for subsidies planned such measures.

At the same time, if you compare Russian and European clusters in terms of the significance of the various types of collaboration for their specialist organizations, some highly characteristic differences arise (Figure 11). One of these relates to the selection of priorities: in Europe, the priority is collaboration between companies in clusters, while in Russia the main concern is to assist in establishing and maintaining a dialogue between business and the state. In all likelihood, representatives of specialist organizations in Russian clusters see the greatest benefit in intensifying collaboration with the authorities, and not in communicating with business partners. In future, it will be important to show participants in Russian pilot clusters the benefits from B2B relations. They will then reduce their dependence on state support, and therefore the risks of revenue-oriented conduct, which constitutes a traditional barrier to the development of the innovation economy.

One other key difference is the minimum value accorded by Russian specialist organizations to working with other clusters. The reason for this lies in the fact that Russian clusters are still far fewer in number and have not existed for as long as their EU counterparts. At the same time, it is worth paying keen attention to this type of collaboration. Benchmarking of core clusters, both Russian and foreign, allows specialist organizations to hone their development strategies and programme: identifying competitive advantages, developing a unique trajectory for technological development, and expanding partnership opportunities.

A key success factor is recognized as the qualifications of cluster policy makers [Christensen et al., 2012, p. 11]. Cluster managers are quick to professionalize their work [INNO Germany AG, 2010, p. 109]: they have set up core associations (TCI Network) and clubs (European Cluster Managers Club) and have drawn up specialist standards [ECEI, 2012] and educational programmes [Kutsenko, 2013]. It is important that national clusters are not left on the sidelines in this process.

It is important to strive for independence from certain participants, especially from influential stakeholders when developing cluster management systems. A specialist organization affiliated with a particular member of a cluster will not 
gain the trust of other partners, making it problematic when it comes to motivating participants and pushing through joint projects.

\section{Active working groups}

A key link in the cluster management system is specialist working groups set up for projects according to the sector and taking into account the size of the participating organizations. Such working groups are noted for their extremely intensive communications in pursuing joint initiatives. Based on the existence and level of activity of such groups, judgements can be made as to whether a cluster actually operates more dynamically whether it is only a means to attract state subsidies. Thus far, working groups have not been set up in all Russian pilot clusters, or their activity is so insignificant that it has not been recorded in the media.

One of the effective forms of working groups could be professional networked communities (associations, clubs, forums) ${ }^{17}$ to cover communications between middle management and specialists and, thus, to contribute to the exchange of information, knowledge and experience [DTI, 2004, pp. 22-24]. In certain Russian clusters, such communities are already functioning. An indicative example is the club for IT directors in the Saint Petersburg ICT cluster. ${ }^{18}$

Fragmentation of intra-cluster communications through working groups becomes particularly important when the number of participants is more than 40; if it exceeds 100 it will be almost the only way to organize effective joint work.

In a number of cases, groups can bring together players from different associations. This is typical of cluster development centres which manage several clusters in one region simultaneously. Thus, in the Upper Austria region, under the patronage of a single centre seven clusters have developed over more than 15 years. It saw the creation of two inter-industry networks ('Human Resource Development' and 'Resource and Energy Efficiency'), participation in which is important for members of all clusters in the region (Figure 12).

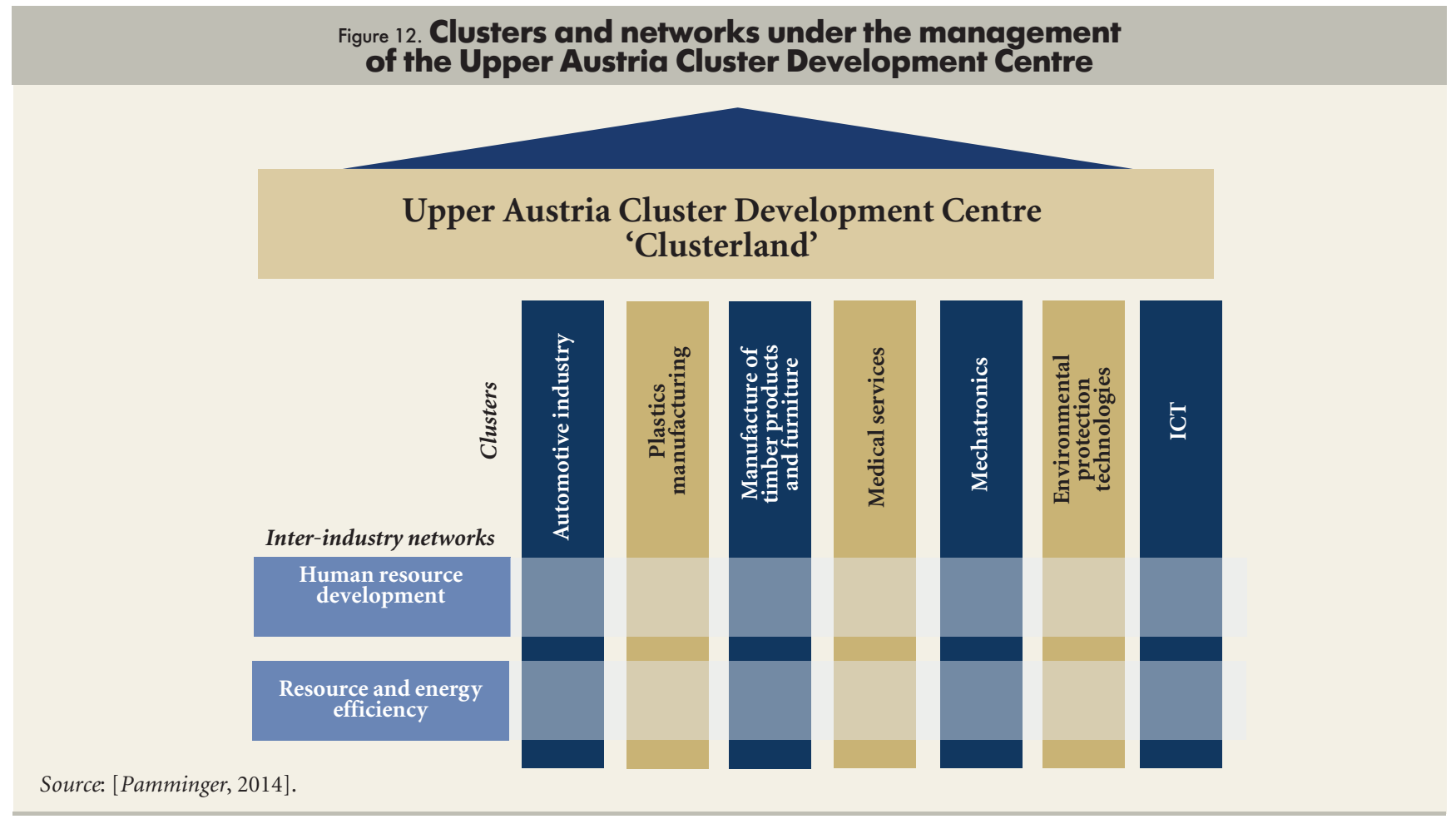

${ }_{17}$ Associations and collective communities (collaboration organizations) are responsible for establishing links in a cluster. As an independent area to expose and discuss common needs, current limitations and opportunities, they can serve as a focal point to concentrate efforts to eliminate or mitigate current problems... In collaboration with local institutes they create training programmes, manage purchasing consortia, develop university-based research programmes, form quality control structures, collect information relating to the cluster's activities, bring up general administrative issues for discussion, research opportunities to solve environmental problems, and control numerous different areas of general interest... For instance, in the Netherlands flower-growing cooperatives set up a specialist auction and processing and storage capacity, which is one of the largest competitive advantages of those in the cluster' [Porter, 1998].

${ }^{18}$ Available at: http://www.spbcioclub.ru, accessed 25.08.2014. 


\section{Formalization of rights, duties and decision-making mechanisms}

The stepping-up of communications helps to democratize interpersonal relations (reduce the power distance). ${ }^{19}$ In an effective cluster, partnership is fundamentally horizontal in nature and assumes equal involvement in decision making. A cluster's strategy is not identical to the interests of the largest organization, the 'finisher' or monopolist, but rather reflects an agreed upon shared vision taking into account the needs of all parties. In reality, break-through projects arise at the juncture of existing potential and skills, technologies that are relevant to a region, Foresight projects and, finally, entrepreneurial talent, through the ability to correctly combine resources and concentrate them in emerging market opportunities.

Local companies, research organizations, universities and authorities have the most complete view of their own technological and market potential. Therefore, decisions (including in relation to joint projects to receive federal subsidies) should be taken by the participants themselves, irrespective of their size and status. We note that horizontal collaboration does not replace relations in vertical value-added chains, but rather exists in parallel, with its own specific goals and rules.

However, in Russian practice, there are numerous instances where large organizations are not prepared to discuss development issues with SMEs, especially if these firms are their suppliers. SMEs, though mentioned on the list of pilot cluster participants, are generally almost unrepresented in clusters' administrative bodies. The system of management where key decisions are taken by senior officials and top managers at state companies does not fully correspond to foreign experience. As a result, rank and file participants are frequently excluded from the decision-making process, and the cluster committee is formed in such a way that only the most influential stakeholders can be members (development institutes, state corporations). At the same time, associations are being set up to bring together all the players. This set-up exists, for example, in many nuclear and radiation technology clusters. The advantage of this approach lies in consolidating figures of authority that are capable of supporting the cluster. However, there are risks of ousting or alienating local communities from the management process, which leads to disenchantment and poor motivation among participants who previously showed enthusiasm. In this case, horizontal collaboration is replaced by vertical approval and competition in the bureaucracy, and the hidden, implicit knowledge of the local community is not called for. The trend of strict subordination of cluster management bodies to regional authorities can cause just as much harm.

To guarantee equality in decision making and the involvement of all interested players in cluster activities, the following recommendations can be made:

- balance the composition of collective administrative bodies (cluster committee, supervisory board of a specialist organization, etc.) with a view to guaranteeing better representation of the various participants (large, medium and small business, higher education institutions, research, financial organizations, etc.) and the accountability of a specialist organization to higher collective administrative bodies; ${ }^{20}$

- develop procedures that entice interested players to draft specialist organization work plans;

\footnotetext{
19 ' One of the greatest surprises of Silicon Valley lies in the fact that, if you want to, you can rub shoulders with virtually anybody you please. In many business spheres it is extremely difficult to get to meet an influential person. In the innovation "tropical rainforest" this can be shockingly simple, as in some places the hierarchy is not so strong; the company structure is horizontal, not vertical'. [Hwang, Horowitt, 2012].

${ }^{20}$ For example, in a number of French clusters (les pôles de compétitivité) they have set up managerial committees, within which they usually establish a committee division responsible for electing the cluster's president (the role of president is often carried out by the representative of a large participating company) and several boards made up of different groups of members. In this way, the board of small and medium enterprises is given four seats; the boards of large enterprises and higher education institutions are given two seats each; and others are given one seat. This system makes it possible to balance out the administrative bodies in such a way that new entrepreneurs and existing SMEs can effectively influence the strategy of the cluster and its management, put forward their own initiatives for joint projects to apply for state support, or join programmes by other participants [Boisson, 2014].
} 
- introduce into the practices of specialist organizations annual reports for cluster members [ECEI, 2012, pp. 12, 23] and regular monitoring of cluster member satisfaction regarding the various aspects of their activities;

- establish open competitive procedures and formal criteria for the selection of projects applying for state funding, and ensure that the maximum possible number of participants are kept informed and involved in this process;

- introduce formalized procedures to join and leave a cluster and set member contributions over time to achieve greater independence and stability in the functioning of specialist organizations.

These measures make it possible to raise the level of institutional development in pilot clusters and to bring it closer to the corporate governance standards set by the OECD [OECD, 2004] (Figure 13). This will help to increase the trust placed in this form of collaboration by local communities, energize old and attract new participants, and balance the development of business activities in the country.

Information on the extent to which the described institutional development measures are implemented in any of Russia's pilot clusters is still absent, although some clusters (for example, the Kamsk Innovative Regional Manufacturing Cluster) are taking active steps in this direction.

There are also other practices geared towards raising trust between cluster participants. Among these are rules (a code) for collaboration, which each party undertakes to abide by upon joining the cluster in signing a corresponding document. This institution allows informal 'club' standards to be introduced, allowing reduced uncertainty in communications with contracting parties and the opportunity to progress further on the path towards forming a new cluster identity. A pioneer in this regard is the Energy Efficient Lighting Technology and Smart Lighting Control Systems cluster (Republic of Mordovia), where rules governing collaboration were established in the agreement to set up the cluster signed by its participants.

Another effective mechanism is the feedback system, which goes beyond specialist organization assessments and helps to accumulate and share collaboration experience (including dishonest conduct) with investors, business agents, innovation infrastructure entities, etc. Clusters' pages on social networks are examples of this. Their value lies in their democracy and openness: anybody wishing to do so can ask a question, join a discussion, and express their opinion on cluster matters. Social networks offer a more favourable environment for free contact, searching for like-minded people and making contacts in comparison to formal measures or forums on official sites. The Sarov, Dimitrovgrad and Khabarovsk clusters all already have social network pages.

\section{Strategic orientation of companies and universities towards innovation}

In recent years, the cluster policy paradigm has been gradually rethought. The focus has shifted from supporting existing leaders and the region's industry specialty to encouraging structural changes, creating new industries by establishing additional value-added chains through restructuring old chains, expanding

\section{Figure 13. Adaptation of OECD corporate governance principles to cluster management}

\section{The cluster management structure must:}

- ensure that it relates to participants fairly, including to SMEs

- ensure that there is effective monitoring of the specialist organization by higher administrative bodies of the cluster (board, cluster committee, etc.) and accountability of higher administrative bodies towards its participants

- allow mechanisms to raise the efficiency with which interested entities participate in the cluster's activities

- ensure that information on all significant aspects of the cluster's activity is disclosed in a timely and accurate way

\section{Participants have right to}

- receive information on the activities of administrative bodies in a timely and regular manner

- participate and vote at general meetings of cluster members

- participate in electing members of higher collective cluster administrative bodies

- participate in decision making to select projects applying for state support

Source: compiled by the author using materials in [OECD, 2004]. 
participant circles, and consolidating links between organizations, among other things. ${ }^{21}$

A decisive factor in competitiveness is the speed with which information spreads between industries and how long it takes to adapt to emerging technologies and replace contracting parties. In this context, the new role of specialist organizations consists of intensifying collaboration between enterprises in different spheres and regions [EFCEI, 2013, pp. 4-5].

It is to be expected that in the majority of European countries a cluster component forms an integral part of innovation policy [Oxford Research, 2008, p. 7]. A significant share of funds allocated to supporting clusters is directed at co-funding joint science, technology and innovation projects. For instance, since 2005, as part of the French cluster programme Les pôles de compétitivité, $738 \mathrm{R} \& \mathrm{D}$ projects, involving 14,000 researchers, received funding totalling 1,470 billion euros. ${ }^{22}$

A focus on innovation, as mentioned above, assumes a high level of trust, allround consideration of interests in decision making and internal competition, which serves as an optimal stimulus for innovation activity. Attempts to institutionally replace it with other mechanisms, for example, by 'forcing' large publicly owned companies to innovate, gives varied results [Gershman, 2013].

Every deal, in particular those linked to delayed fulfilment of obligations, holds an element of trust between contracting parties [Arrow, 1972]. A lack of trust leads to an increase in corresponding expenses, in some cases making the transaction economically ill-advised. The innovation activity of forms is particularly sensitive to this factor, as it is common for things to be done outside formal contracts, with heightened uncertainty. Parity in decision making requires institutional mechanisms that restrict the dominance of one organization or consortium in a cluster, clearly defining the powers, service length, accountability and renewal procedure of administrative bodies, and establishing transparent procedures for the entry of new participants and including them in the projects being supported.

The rules described form 'an inclusive institutional system' on a local level. The economic historians Daron Acemoglu and James A. Robinson suggest that it is only such institutions (in contrast to an 'exclusive institutional system') that serve as a reliable platform from which to start a long-term innovation process. This can be explained by the fact that the latter term, according to Schumpeter, consists in constant 'creative destruction', which draws in bearers of creative ideas who propose new solutions to old problems, and leads to a change in the make-up of the economic and (with time) political elite. It is precisely as a result of these circumstances that an innovative developmental path is of ten not called for; the ruling circles try with all their might to keep the status quo and to restrict vertical social mobility and, as a result, competition [Acemoglu, Robinson, 2012].

A corporation or a cluster is a micro-model of society; their innovation activity is in many ways dependent on which local institutions operate in them. Since successful innovative companies exist even in institutionally deficient conditions, it is also possible to establish productive innovative clusters geared towards 'creative destruction'.

However, for a cluster to be a source of new ideas, projects and teams, the aforementioned infrastructural and institutional conditions are not enough. Innovative advantages, like a decline in transport costs, cannot only be guaranteed through collaborative localization of manufacturers and buyers. Welltargeted, regular efforts to build communications with one another on the part of different participants are needed to develop new products.

The most fitting corporate strategy, giving rise to innovative advantages and the associated gains, is based on an 'open innovations' model [Chesbrough, 2003;

\footnotetext{
${ }^{21}$ In 2012-2013, the European Cluster Observatory, together with PwC, developed a methodology to identify so-called emerging industries in the EU, which are the result of establishing new or radically transforming existing value-added chains [European Cluster Observatory, 2012], in addition to a tool kit to appraise their development in certain regions with regard to the viability of establishing world-class clusters [European Cluster Observatory, 2013].

${ }^{22}$ Available at: http://www.industrie.gouv.fr/poles-competitivite/brochure-en.html, accessed 01.11.2012.
} 
Chesbrough et al., 2006; Vrande et al., 2009]. ${ }^{23}$ However, implementing this model in practice is difficult for several reasons, in particular due to the rejection of corporate culture. An example is the 'not invented here' syndrome, which reflects a distrust of results obtained outside the research division of a particular company. The spread of an open innovation strategy is also dependent on the overall level of development of the business environment and trust in the company. Sometimes, rejection of such a strategy can be explained by a rational desire to minimize risks and administrative expenses. Therefore, favourable conditions for the associated transactions presuppose the market prevalence of innovations by intermediaries - technology alliances, platforms, networks, clusters, etc. - which offer the necessary information, contacts, channels of influence, and funding. A dependence on the external environment forces players implementing an open innovation strategy to focus their attention, primarily, on partnerships with nearby organizations.

A study of R\&D globalization processes carried out by INSEAD in collaboration with Booz Allen Hamilton looked at 189 companies from 17 sectors and 19 countries. The study found that collaboration by transnational companies with external entities (universities, customers, suppliers, alliance partners) tends to gravitate towards significant spatial concentration, and the location of their headquarters are collaboration localization zones [INSEAD, Booz Allen Hamilton, 2006, pp. 8-9]. Another study reached a similar conclusion [OECD, 2008, pp. 17-18]. In a number of cases, large companies situate their research divisions in locations where there are strong research organizations, universities and innovative enterprises. In this way, the pharmaceutical company Novartis concentrates its scientific and technological activity in dynamic biotechnology clusters in Basel, San Diego and Boston, each of which has its own specialism and competitive advantages [Cooke, 2005].

As such, the formation of clusters is closely linked to the implementation of an open innovation strategy in corporations. This model is called for in network research activity involving many organizations, when the business environment and intermediaries reduce the level of transaction costs, stimulating growth in innovation deals. At the same time, the more open a company's innovation activity becomes, the more important its involvement in a cluster. Pursuing open innovations contributes to intensifying inter-firm partnerships, the involvement of new players in a region, and the creation of a belt of small innovative enterprises around industrial giants.

At the same time, the corporate strategies of 'cluster involvement' and 'open innovations' are not identical. Aside from some overlaps, each strategy has its own sphere of implementation (Figure 14). As we can see, involvement in a cluster is not restricted to innovative activity and, likewise, not all open innovation mechanisms are sensitive to the geographical proximity factor. At the juncture of the two concepts mentioned above, an open innovation clustering strategy emerges: the targeted and systematic application of an open scheme in collaboration with other participants.

We note that implementing such an approach requires a significant resource commitment to making contacts, forming networks, organizational restructuring, changing the assessment criteria of innovation activity, and forming knowledge management systems [Chiaroni et al., 2011; Guinet, Meissner, 2012]. Therefore, success in following an open innovation cluster strategy will be determined primarily by the presence of large companies. An investigation into innovation activity in European countries showed results that were anticipated: large companies collaborate four times more frequently with other organizations than SMEs [OECD, 2008, p. 14]. According to another study, SMEs only

\footnotetext{
${ }^{23}$ For the first time, the open innovations concept proposed by Henry Chesbrough in 2003 [Chesbrough, 2003] gained widespread popularity among both practitioners and researchers (a search on Google Scholar with the query 'open innovations' in 2010 showed more than 2 million mentions [Huizingh, 2011]). Open innovations are understood to mean well-targeted use of incoming and outgoing knowledge flows to stimulate innovation activity within a firm and expand markets to make use of the results [Chesbrough et al., 2006]. Generally speaking, in the 'open innovations' model, two strategies are singled out: incoming (attracting outside solutions) and outgoing (use of internal developments) [Chesbrough et al., 2006; Huizingh, 2011]. The first uses tools such as R\&D outsourcing, the acquisition of companies and intellectual property, network collaboration, and the involvement of buyers. The second implies the creation of new companies, the sale of intellectual property (licensing) and the involvement of staff in innovation activity [Vrande et al., 2009].
} 


\section{Figure 14. General and special cluster strategy instruments and open innovation strategies}

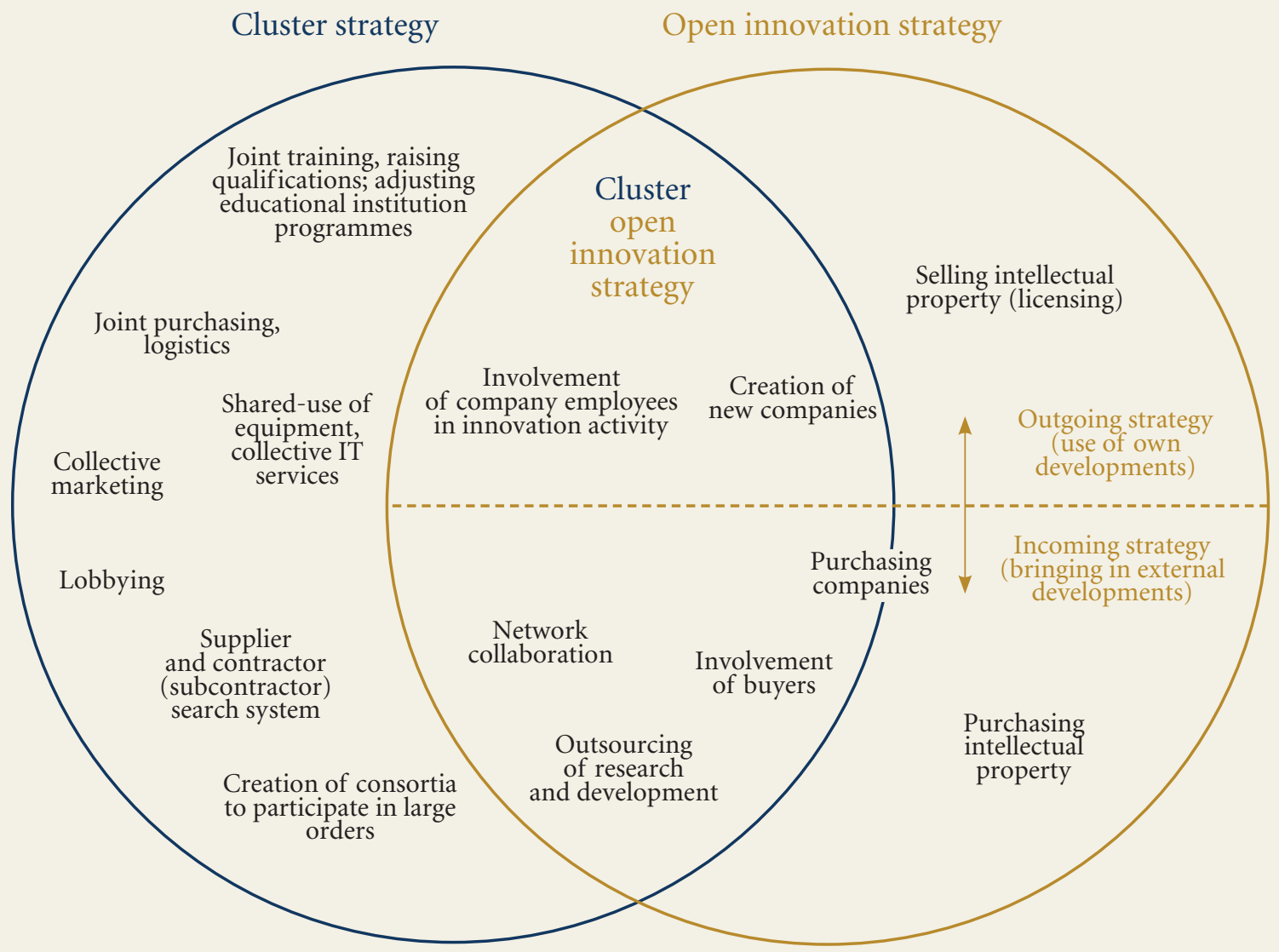

Source: compiled by the author.

use certain open innovation instruments, and only extremely rarely resort to buying and selling licences, venture capital and R\&D outsourcing [Vrande et al., 2009].

Besides, the role of change generator can be played by universities. ${ }^{24}$ The implementation by universities of an 'entrepreneurial higher educational institution' model, which has much in common with open innovation strategies, has led to the emergence of clusters in a number of cases. A proportion of these associations are on the list of pilot clusters (the Information Technology and Electronics cluster in Tomsk region and Phystech XXI), while others either did not make it through the competitive selection process (Tambov Bioeconomic Cluster) or were established later (Moscow composite and medical clusters).

We will now dwell in more detail on two key tools of a cluster-type open innovation strategy: the implementation of joint projects with other participants (incoming strategy) and the establishment of a belt of innovative start-ups around large companies or universities (outgoing strategy).

\section{Joint innovation projects}

Clusters should not be viewed solely as a tool to achieve certain set goals and carry out existing projects. Above all, they constitute an environment which is recognized to generate innovative initiatives, for which the ability (and desire) to accept new ideas and forms of partnership, identify weak signals in good

\footnotetext{
${ }^{24}$ It is not by chance that the European system of assessing the quality of management in clusters includes criteria such as it being mandatory for the university and/or research organization to be listed as official participants [Hagenauer et al., 2012, p. 2]. All Russian pilot clusters comply in full with this criterion. Moreover, the proportion of universities and research organizations in the total number of participants is even higher than in European clusters (excluding Iceland) (see Figure 8 above). What is more, in EU countries the main goal of state cluster policy is often to stimulate innovation and links between business and research [INNO Germany AG, 2010, p. 36]. This is typical, above all, in the United Kingdom, Germany, Denmark, Iceland, Latvia, Norway, Romania, and Slovakia. Cluster initiatives are more often coordinated with R\&D support programmes as opposed to business or infrastructure development [Müller et al., 2012, pp. 43-46, 60].
} 
time, show flexibility, and encourage collaboration are all necessary. It is advisable to focus on supporting joint innovation projects and blocking autonomous projects, even if the aim of such projects is said to be the development of the cluster as a whole [DTI, 2004, p. 38].

\section{Belt of innovation start-ups around large companies or universities}

The success of a cluster strongly depends on whether it can manage to guarantee an influx of new enterprises [Christensen et al., 2012, p. 26]. An indicative example of this is 11 projects by the company Xerox, which 'broke off' into separate firms (spin-offs), and their combined income over time surpassed the revenue of the parent structure by twofold [Chesbrough, 2003].

In a number of cases, clusters themselves arise as a result of a long and productive process of division of new firms from universities or anchor companies [DTI, 2004, p. 35]. The comparison given in Figure 2 above with industries where foreign clusters are developing shows that in Russia there are significant reserves in sectors such as the food industry, green technology, medical services, metallurgy, the textile industry, transport and logistics, agriculture, construction, manufacturing technologies, and creative industries.

However, in the majority of countries, cluster policy is, as before, focused on supporting existing enterprises by stimulating their innovative development through the creation of cooperative links. Only a small number of state cluster programmes in European countries are geared towards the development of start-ups. Among the pioneers in this regard is the Finnish programme OSKE [Müller et al., 2012, p. 44].

In relation to this, an important aspect of innovation policy is shifting the focus to start-ups, spin-offs, dynamic SMEs ('gazelles'), as well as to an ecosystem that is conducive to exchanging ideas, developing corresponding projects and business plans, searching for partners and investors, and setting up teams. In such a paradigm, the specialist organizations of clusters are becoming the connecting link between different elements of a regional innovation ecosystem - universities, research organizations, and innovation infrastructure - by directing and coordinating their activities [Christensen et al., 2012, p. 10].

The significance of cluster policy should grow as an industry comes of age, when former start-ups encounter problems in expanding their activities. These problems include underdeveloped manufacturing infrastructure, lack of equipment and qualified work force, poor positioning on the global market, and inadequate communication with state authorities and research institutes. Associating in clusters helps to effectively overcome these barriers.

Recently, the development of innovation start-ups in pilot clusters has grown in importance in Russia. An analysis of federal subsidy programmes at the end of 2013 showed that the majority planned to establish an innovation infrastructure, to a greater or lesser extent geared towards these challenges. These were at engineering centres in the Kaluga, Novosibirsk, and Krasnoyarsk regions. A BioBusiness Incubator already exists in the Phystech XXI cluster, with a Biopharmaceutical building and ICT technology park under construction. In the context of the collaboration between the Innovative Nuclear Physics and Nanotechnology Regional Cluster in Dubna and the state corporation Russian Venture Capital (OAO RVK), there are plans to set up a technology enterprise centre and participate in the 'Regional Business Catalyst' project. The formation of an intra-cluster venture capital fund has been mentioned in programmes in the Republic of Tatarstan and Ulyanovsk region (in the city of Dimitrovgrad).

A unique case is the creation of a pre-incubator in the Zelenograd cluster, where thanks to a federal subsidy they built specialist infrastructure to encourage technology start-ups. ${ }^{25}$

The role of clusters as generators of innovative joint projects and start-ups is of great importance to the national innovation system in Russia. The lack of

\footnotetext{
${ }^{25}$ Unlike a common business incubator, a pre-incubator supports new enterprises not only at the 'start-up' stage, but at the 'ideas' stage. Its services consist of providing work space, computers and office equipment, consultancy, assistance in drawing up business plans and project presentations, development recommendations, and support in company registration.
} 
attractive projects is becoming a clear pinch point for the country's economy. Only with time will we know the extent to which pilot cluster development programmes help to solve this problem.

\section{The 'Anna Karenina Principle': Signs of sustainable cluster development}

The 'Anna Karenina Principle' can be illustrated with a phrase from Tolstoy's novel: 'All happy families are alike; each unhappy family is unhappy in its own way.' [Tolstoy, 1999]. Jared Diamond used it to describe the process of animal domestication which ended in success when several groups of factors coincided. Out of the 148 large, land-based herbivorous mammals that existed in the world and might have been domesticated, only 14 passed the suitability test ('happy families'). The remaining 134 types were among the 'unhappy families', each with their own unique formula [Diamond, 1997]. Such an observation is also fair in terms of explaining the success of state efforts to establish sustainable clusters which are characterized by the presence of all the - often interrelated - signs described above (Figure 15 below).

A developed urban environment and a significant number of core companies and associated entities create the necessary prerequisites for greater communication and establish a foundation for potential self-organization (both in the form of horizontal professional or industry associations, and in the form of specialist cluster organizations). In turn, a high degree of trust and intensive internal collaboration contribute to pushing through new ideas and projects, including by creating start-up companies. Ultimately, an innovative ecosystem with an inherent culture of change is a significant element of an urban environment which stimulates the dynamics of existing clusters and the emergence of new ones. Synergy between the aforementioned groups of factors gives successful clusters stability, but the lack of one or more 'ingredients' can sharply diminish the chances of embarking on a trajectory of self-sustaining growth.

We have shown in this article that there are pilot clusters in Russia that do not fully correspond with almost all the signs listed above.

Thus, the development of many clusters situated outside the administrative centres of the corresponding regions is held back by the real quality of the urban environment. The risks caused by being part of a single-specialty and closed city is particularly high, which is clear in the Innovative Technologies Cluster in the Zheleznogorsk closed city (ZATO), the Sarov Innovation Cluster, the Shipbuilding Innovative Regional Cluster in Arkhangelsk region, and the Nuclear Innovation Cluster in Dimitrovgrad (Ulyanovsk region).

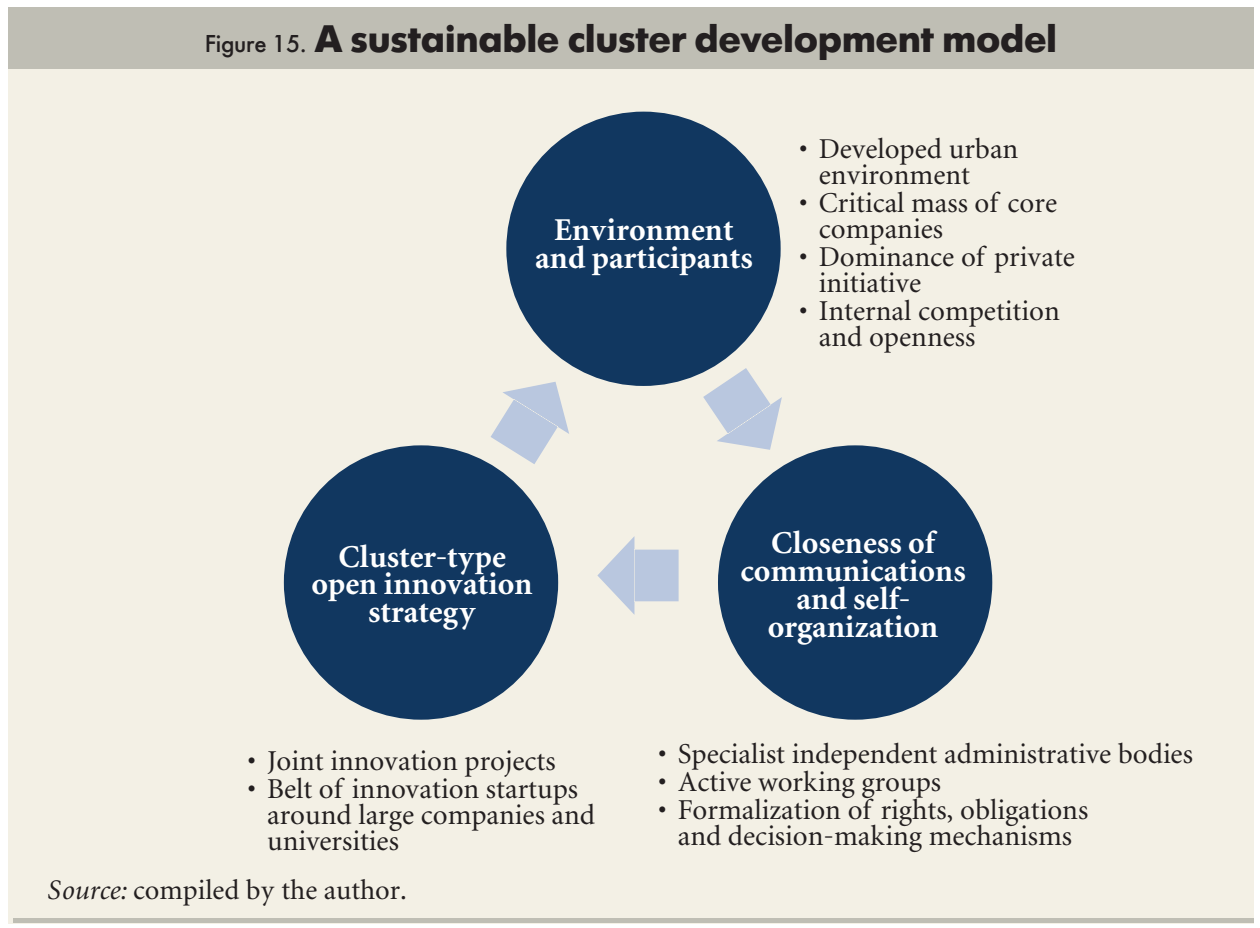


As yet, Russian clusters have not yet reached a critical mass of core participating companies. Above all, this is seen in areas such as new materials, nuclear and radiation technologies, aerial and space instrument manufacturing, and ship building. Innovative technology clusters in the Zhelezngorsk closed city and radiation technology clusters (Saint Petersburg and Leningrad region), the Shipbuilding Innovative Regional Cluster (Arkhangelsk region), the Titanium Cluster (Sverdlovsk region), and the Energy Efficient Lighting Technology and Smart Lighting Control Systems cluster (Republic of Mordovia) all have less than 20 participants.

A significant shortcoming of virtually all the pilot clusters is the insignificant contribution of business and the lack of internal competition. This is less the case for clusters in the ICT, electronics, pharmaceuticals, biotechnology and medical industries. At the bottom end of the scale, in ten pilot clusters the proportion of companies is extremely low at less than $50 \%$.

In clusters in the city of Moscow and the Moscow, Tomsk and Novosibirsk regions, there was a drastic increase in the role of regional authorities in 2013, which raises the question of coordinating the interests of businesses and the state in specialist organizations.

We hypothesised that the level of trust among participants should significantly increase in connection with implementing a whole range of measures in the short-term, including educational programmes, raising the qualifications of cluster managers, active work by permanent cluster administrative bodies, and the gradual formation of collaboration frameworks and 'cluster participant specialist organization' feedback systems. It can be expected that the level of trust in the first group of pilot clusters will grow rapidly, since these measures were in many cases supported by the state as far back as 2013 .

As for institutional development to guarantee equality in decision making and the impartiality of administrative bodies, reliable information on the successes of pilot clusters is still clearly unavailable. Horizontal professional communities only operate in some of them, which are generally situated in large cities with many core companies.

As for the signs characterizing a strategic orientation on the part of cluster entities towards an open innovation model, policies to increase the number of standards and rapidly develop SMEs have had a mixed record to date. A policy of setting up new companies and nurturing 'gazelles' has only fully been reflected in the development programme of one cluster, the one in Zelenograd. Nonetheless, virtually all clusters are creating specific innovation infrastructure (primarily, engineering centres), which is to a greater (Novosibirsk region) or lesser (Republic of Mordovia or Krasnoyarsk region) extent honed to the needs of SMEs.

The question of joint innovation projects emerging in Russian clusters currently def ies objective assessment. This is due to the fact that, unlike in the majority of European programmes, in Russia there is no distinction between the notion of infrastructural support for pilot clusters through funding the activities of specialist organizations and stimulating joint innovative projects. Despite the fact that a recent government resolution [Government of the Russian Federation, 2013] made provisions for joint projects to be carried out on the back of federal subsidies, the selection criteria do not include any requirements on participant numbers, innovative components, or the level of extra-budgetary funding. Policies need to be adjusted accordingly to encourage participants to develop joint innovation projects for future expert assessment.

Taking into account the numerous shortcomings in all pilot clusters of Russia, it is particularly important to identify their strengths and weaknesses. Such an analysis will make it possible to come close to selecting an individual set of support measures for each specific case or to refuse support, if the defects are too great. Sometimes, problem solving requires the use of other instruments, including those not connected with cluster policy.

Regular monitoring of supported structures is no less important a task, as it allows the state funding programme to be adjusted over time [Christensen et al., 2012, p. 11]. 


\section{Conclusion}

In global practice, there is considerable experience in implementing cluster support programmes and studies have identified the factors underpinning their success. In Russia, state support for clusters is at an early stage, currently covering 25 pilot groups selected based on the results of a competitive tender in 2012. In order to assess the results of these pilots, the necessary methodological and organizational work needs to be done in the near future.

This article aims to fill a vacuum by analysing development programmes and focusing on pilot clusters. A comparison with equivalent foreign parameters and state programmes made it possible to formulate certain key conditions for sustainable cluster development, including the quality of the urban environment, a critical mass of core companies, the dominance of private initiatives, internal competition and openness, and the existence of specialist independent administrative bodies and active working groups. These bodies and groups clarify rights, duties and decision-making mechanisms, carry out joint innovation projects, and establish a belt of innovative start-ups around large companies or universities.

The ability of a cluster to demonstrate all of the aforementioned key conditions would imply a substantial transformation, which would enable the cluster to set off on a path of self-sustaining development. Such establishments will continue to develop and, after state support has ended, will become drivers for economic growth in their corresponding regions. The assessment of pilot clusters with the noted conditions showed that they all, to a greater or lesser extent, exhibit clear shortcomings. Therefore, their development strategy and the state support measures require some adjustment.

\section{References}

Abashkin V., Boyarov A., Kutsenko E. (2012) Klasternaya politika v Rossii: ot teorii k praktike [Cluster Policy in Russia: From Theory to Practice]. Foresight-Russia, vol. 6, no 3, pp. 16-27 (in Russian).

Acemogly D., Robinson J. (2012) Why Nations Fail: The Origins of Power, Prosperity, and Poverty, New York: Crown Business.

Arrow K. (1972) Gifts and Exchanges. Philosophy and Public Affairs, vol. I, no 4, pp. 343-362.

Boisson J.-F. (2014) France Clusters. Paper presented at the workshop forum for innovation clusters in nuclear energy, aviation, biotech and medicine, 8-11 December 2014, Dimitrovgrad, Ulyanovsk region.

Chesbrough H., Vanhaverbeke W., West J. (2006) Open Innovation: Researching a New Paradigm, Oxford: Oxford University Press.

Chesbrough H. (2003) Open Innovation: The New Imperative for Creating and Profiting from Technology, Boston: Harvard Business School Press.

Chiaroni D., Chiesa V., Frattini F. (2011) The Open Innovation Journey: How Firms Dynamically Implement the Emerging Innovation Management Paradigm. Technovation, vol. 31, no 1, pp. 34-43.

Christensen T.A., Lämmer-Gamp T., Meier zu Kôcker G. (2012) Lets make a perfect cluster policy and cluster programme. Smart recommendations for policy makers, Berlin: VDI/VDE Innovation + Technik GmbH (VDI/VDE-IT).

CLOE (2004) Cluster Management Guide - Guidelines for the Development and Management of Cluster Initiatives, Linz: TMG Technologie- und Marketinggesellschaft m.b.H. of Upper Austria.

Cooke P. (2005) Regionally Asymmetric Knowledge Capabilities and Open Innovation. Exploring 'Globalisation 2' A New Model of Industry Organisation. Research Policy, vol. 34, no 8, pp. 1128-1149.

DGCIS, DATAR, SGAR, DIRECCTE (2012) Competitiveness Clusters in France, Paris: The Directorate General for

Competitiveness, Industry and Services (DGCIS), Interministerial Agency for Land Management and Regional Business Development (DATAR), The General Secretariats for Regional Affairs (SGAR), The Regional Directorates for Businesses, Competition Policy, Consumer Affairs, Labour and Employment (DIRECTE ) - 'Businesses, Employment and Economy' unit. Available at: http://competitivite.gouv.fr/documents/commun/Documentation_poles/brochures_poles/anglais/brochure-anginternet.pdf, accessed 01.11.2012.

Diamond J. (1997) Guns, Germs, and Steel: The Fates of Human Societies, New York, London: W. W. Norton \& Company.

Dohse D., Staehler T. (2008) BioRegio, BioProfile and the Rise of the German Biotech Industry (Working Paper no 1456), Kiel: Kiel Institute for the World Economy. Available at: https://www.ifw-members.ifw-kiel.de/publications/bioregio-bioprofile-and-thegrowth-of-the-german-biotech-industry/KWP 1456.pdf, accessed 15.06.2014.

DTI (2004) A Practical Guide to Cluster Development: A Report to the Department of Trade and Industry and the English RDAs, London: DTI.

ECEI (2012) The Quality Label for Cluster Organisations - Criteria, Processes, Framework of Implementation, European Cluster Excellence Initiative. Available at: http://www.cluster-excellence.eu/fileadmin/_cluster-excellence/downloads/GOLDAssessment.pdf, accessed 23.07.2014.

EFCEI (2013) Extension of the European Cluster Observatory: Promoting Better Policies to Develop World-class Clusters in Europe. A Policy Roadmap for Stimulating Emerging Industries, Brussels: European Commission. Available at: http://www. emergingindustries.eu/Upload/CMS/Docs/Policy_roadmap.pdf, accessed 23.07.2014.

Eickelpasch A. (2008) The promotion of regional innovative networks - Lessons from the German InnoRegio-Programme. Paper presented at the Final DISTRICT Conference 'Innovation Pathways and Knowledge Economy', April 16, Brussels.

European Cluster Observatory (2012) 'Emerging industries': Report on the methodology for their classification, on most active and successful newly emerging industrial sectors, and on their geographical localization, Brussels: European Commission. Available at: http://www.clusterobservatory.eu/system/modules/com.gridnine.opencms.modules.eco/providers/getpdf.jsp?uid=4889e7e787fd-4a70-a6e2-0c6b170cb890, accessed 23.07.2014.

European Cluster Observatory (2013) European Cluster Excellence Scoreboard. Pilot Version, Brussels: European Commission. Available at: http://www.emergingindustries.eu/Upload/CMS/Docs/ECES_Pilot.pdf, accessed 23.07.2014.

European Comission (2007) Innovation Clusters in Europe: A Statistical Analysis and Overview of Current Policy Support (DG Enterprise and Industry Report), Brussels: European Commission. Available at: http://www.central2013.eu/fileadmin/user upload/Downloads/Tools_Resources/Cluster.pdf, accessed 24.09.2014. 
European Commission (2006) 2006 Innobarometer on cluster's role in facilitating innovation in Europe, Brussels: European Commission.

Florida R.L. (2002) The rise of the creative class: And how it's transforming work, leisure, community and everyday life, New York: Basic Books.

Gershman M. (2013) Programmy innovatsionnogo razvitiya kompanii s gosudarstvennym utchastiem: pervye itogi [Innovation Development Programmes for the State-owned Companies: First Results]. Foresight-Russia, vol. 7, no 1, pp. 28-43 (in Russian).

Golovanova S.V., Avdasheva S.B., Kadotchnikov S.M. (2010) Mezhfirmennaya kooperatsiya: analiz razvitiya klasterov v Rossii [Inter-firm Cooperation: Analysis of Clusters' Development in Russia]. Rossiiskii zhurnal menedzhmenta [Russian Management Journal], vol. 8, no 1, pp. 41-66 (in Russian).

Government of the Russian Federation (2013) Pravila raspredeleniya i predostavleniya subsidii iz federal'nogo byudzheta byudzhetam sub"ektov Rossiiskoi Federatsii na realizatsiyu meropriyatii, predusmotrennykh programmami razvitiya pilotnykh innovatsionnykh territorial'nykh klasterov. Utverzhdeny Postanovleniem Pravitel'stva Rossiiskoi Federatsii № 188 ot 06.03.2013 (v redaktsii izmenenii, utverzhdennykh Postanovleniem Pravitel'stva Rossiiskoi Federatsii № 596 ot 15.07. 2013) [Rules for the allocating subsidies from the federal budget of the Russian Federation on the implementation of activities under the pilot program of innovative regional clusters. Approved by the Resolution of the Government of the Russian Federation no 188 dated 06.03.2013 (as amended by the changes approved by the RF Government Decree no 596 dated 15.07.2013)]. Available at: http://www.consultant.ru/document/cons_doc_LAW_168824/, accessed 24.12.2014 (in Russian).

Guinet J., Meissner D. (2012) Otkrytye innovatsii: effekty dlya korporativnykh strategii, gosudarstvennoi politiki i mezhdunarodnogo 'peretoka' issledovanii i razrabotok [Open Innovation: Implications for Corporate Strategies, Government Policy and International R\&D Spillovers]. Foresight-Russia, vol. 6, no 1, pp. 26-36 (in Russian).

Hagenauer S., Kergel H., Stürzebecher D. (2012) European Cluster Excellence BASELINE - Minimum Requirements for Cluster Organisations, European Cluster Excellence Initiative. Available at: http://www.cluster-excellence.eu/fileadmin/_clusterexcellence/grafiken/20111128 European Cluster Excellence BASELINE_web.pdf, accessed 23.07.2014.

HSE (2013) Pilotnye innovatsionnye territorial'nye klastery v Rossiiskoi Federatsii [Pilot innovative regional clusters in Russia] (eds. L. Gokhberg, A. Shadrin), Moscow: HSE (in Russian).

Huizingh E. (2011) Open Innovation: State of the Art and Future Perspectives. Technovation, vol. 31, no 1, pp. $2-9$.

Hwang V.W., Horowitt G. (2012) The Rainforest: The Secret to Building the Next Silicon Valley, California: Regenwald.

INNO Germany AG (2010) Clusters and clustering policy: A guide for regional and local policy makers, Brussels: European Commission. Available at: http://cor.europa.eu/en/Archived/Documents/59e772fa-4526-45c1-b679-1da3bae37f72.pdf, accessed 24.01.2014.

INSEAD Booz Allen Hamilton (2006) Innovation: Is Global the Way Forward? Survey results, McLean: Booz Allen Hamilton. Available at: http://www.boozallen.com/media/file/Innovation_Is_Global_The_Way_Forward_v2.pdf, accessed 07.10.2014.

Ketels C. (2013) Recent research on competitiveness and clusters: What are the implications for regional policy? Cambridge Journal of Regions, Economy and Society, vol. 6, no 2, pp. 269-284.

Kutsenko E. Meissner D. (2013) Key Features of the First Phase of the National Cluster Program in Russia (HSE Research Paper no WP BRP 11/STI/2013), Moscow: HSE. Available at: http://dx.doi.org/10.2139/ssrn.2253377, accessed 24.01.2014.

Kutsenko E.S. (2013) Upravlenie klasterom kak professiya [Cluster Management as a profession]. Paper presented at the Cluster Summit, November 14-15, Moscow. Available at: http://www.slideshare.net/evgenykutsenko/2013-28272059, accessed 24.01.2014 (in Russian).

Lindqvist G., Ketels C., Sölvell Ö. (2013) The Cluster Initiative Greenbook 2.0, Stockholm: Ivory Tower Publishers.

Menzel M.-P., Fornahi D. (2007) Cluster Life Cycles - Dimensions and Rationales of Cluster Development (Jena Economic Research Paper no 2007-076), Jena: Friedrich-Schiller-University Jena, Max-Planck-Institute of Economics. Available at: http:// www.econstor.eu/dspace/bitstream/10419/25650/1/553691740.PDF, accessed 24.01.2014.

Ministry of Economic Development (2012) Strategiya innovatsionnogo razvitiva Rossiiskoi Federatsii na period do 2020 goda (utverzhdena rasporyazheniem Pravitelstva RF no 2227-p ot 08.08.2011) [Innovative Development Strategy for the Russian Federation until 2020 (Approved by the Government of the Russian Federation (Approved by the Resolution of the Government of the Russian Federation no 2227-r dated 08.08.2011)], Moscow: Ministry of Economic Development of the Russian Federation. Available at: http://www.economy.gov.ru/minec/activity/sections/innovations/doc20120210_04, accessed 28.06.2014 (in Russian).

Müller L., Lämmer-Gamp T., Meier zu Kôcker G., Christensen T.A. (2012) Clusters are individuals. New findings from the European cluster management and cluster program benchmarking (vol. II), Berlin: VDI/VDE Innovation + Technik GmbH (VDI/VDE-IT)

OECD (2004) OECD Principles of Corporate Governance, Paris: OECD.

OECD (2007) Competitive Regional Clusters: National Policy Approaches, Paris: OECD.

OECD (2008) Open Innovation in a Global Perspective — What Do Existing Data Tell Us? (STI Working Paper 2008/4), Paris: OECD. Available at: http://www.oecd.org/sti/ind/41885837.pdf, accessed 07.10.2014.

Oxford Research (2008) Cluster policy in Europe. A brief summary of cluster policies in 31 European countries, Kristiansand, Norway: Oxford Research AS. Available at: http://www.clusterobservatory.eu/system/modules/com.gridnine.opencms.modules. eco/providers/getpdf.jsp?uid=100146, accessed 24.01.2014.

Pamminger W. (2014) Cluster Academy Workshop: Learning from a 'cluster region'. Presentation at the 17th TCI Global Conference 'Creating shared value through clusters for a sustainable future', 10-13 November 2014, Monterrey, Mexico. Available at: http:// www.slideshare.net/TCINetwork/tci2014-11-novclusterlabswerner-pamminger, accessed 22.01.2015.

Porter M. (1990) The Competitive Advantage of Nations, New York: The Free Press.

Porter M. (1998) On Competition, Boston: Harvard Business School.

Porter M. (2003) The Economic Performance of Regions. Regional Studies, vol. 37, no 6-7, pp. 549-578.

Pro Inno Europe (2009) INNO-PolicyTrendChart, Brussels: European Commission. Available at: http://proinno.intrasoft.be/index. $\mathrm{cfm}$ ?fuseaction=wiw.measures\&page= detail\&ID=8922, accessed 26.07.2012.

Pro Inno Europe (2012) Key messages and practical recommendations from the TACTICS project, Brussels: European Commission. Available at: http://www.vinnova.se/upload/EPiStorePDF/Tactics_KeyMessages.pdf, accessed 24.01.2014.

RVC, HSE, CSR 'North-West' (2014) Sistema menedzhmenta dlya upravlyayushchikh kompanii innovatsionnykh territorial'nykh klasterov Rossiiskoi Federatsii [The management system for managing companies of innovative regional clusters of the Russian Federation], Moscow: Russian Venture Company. Available at: http://www.rusventure.ru/ru/programm/analytics/docs/201403 management_companies_clusters.pdf, accessed 12.10.2014 (in Russian).

Sarov.Net (2014) A den'gi davali. Shantsev raskritikoval ideyu Sarovskogo klastera [And the money was given. Shantsev criticized the idea of Sarov cluster]. Sarov.Net, 24.01.2014. Available at: http://www.sarov.net/news/?id=29399, accessed 14.10.2014 (in Russian).

Sölvell Ö., Lindqvist G. (2013) The Cluster Initiative Greenbook 2.0. Presentation at the 16th TCI Global Conference 'Designing the Future - Innovation through Strategic Partnerships', 3-6 September 2013, Kolding, Denmark. Available at: http://www. slideshare.net/TCINetwork/tci2013-5-septplenarygran-lindqvistrian-slvell, accessed 22.01.2015.

Sölvell Ö., Lindqvist G., Ketels C. (2003) The Cluster Initiative Greenbook, Stockholm: Bromma Tryck AB.

Tolstoy L. (1999) Anna Karenina: roman [Anna Karenina: A novel], Moscow: Open Society Institute, SLOVO. ISBN 5-85050$382-\mathrm{X}$ (in Russian).

Vikulova A. (2013) Mernyi atom. Sarovskii innovatsionnyi klaster mozhet ostat'sya bez federal'noi podderzhki v 2014 godu [Measuring the atom. Sarov innovation cluster may remain without federal support in 2014]. Kommersant, 21.11.2013. Available at: http://www.kommersant.ru/doc/2341115, accessed 14.10.2014 (in Russian)

Vrande V., de Jong J.P.J., Vanhaverbeke W., de Rochemont M. (2009) Open innovation in SMEs: Trends, motives and management challenges. Technovation, vol. 29, no 6-7, pp. 423-437. 